\title{
Current and Novel Alkylators in Multiple Myeloma
}

\author{
Fredrik Schjesvold ${ }^{1,2, *(D)}$ and Albert Oriol ${ }^{3}$ \\ 1 Oslo Myeloma Center, Oslo University Hospital, 0450 Oslo, Norway \\ 2 K.G. Jebsen Centre for B-Cell Malignancies, University of Oslo, 4950 Oslo, Norway \\ 3 Institut Josep Carreras and Institut Català d'Oncologia, Hospital Germans Trias I Pujol, \\ 08916 Badalona, Spain; aoriol@iconcologia.net \\ * Correspondence: fredrikschjesvold@gmail.com; Tel.: +47-99-697-796
}

check for

updates

Citation: Schjesvold, F.; Oriol, A Current and Novel Alkylators in Multiple Myeloma. Cancers 2021, 13, 2465. https://doi.org/10.3390/ cancers 13102465

Academic Editor: Klaus Podar

Received: 3 March 2021

Accepted: 11 May 2021

Published: 18 May 2021

Publisher's Note: MDPI stays neutral with regard to jurisdictional claims in published maps and institutional affiliations.

Copyright: (C) 2021 by the authors. Licensee MDPI, Basel, Switzerland. This article is an open access article distributed under the terms and conditions of the Creative Commons Attribution (CC BY) license (https:/ / creativecommons.org/licenses/by/ $4.0 /)$.
Simple Summary: In this review we have summarized the history, the current use, and the future possibilities of alkylator treatment in multiple myeloma. Alkylators have for decades been part of the standard of care of myeloma treatment, but still new alkylators and new use of old alkylators are making its way into myeloma guidelines of today.

Abstract: A large number of novel treatments for myeloma have been developed and approved; however, alkylating drugs continue to be part of standard regimens. Additionally, novel alkylators are currently being developed. We performed a non-systematized literary search for relevant papers and communications at large conferences, as well as exploiting the authors' knowledge of the field, to review the history, current use and novel concepts around the traditional alkylators cyclophosphamide, bendamustine and melphalan and current data on the newly developed pro-drug melflufen. Even in the era of targeted treatment and personalized medicine, alkylating drugs continue to be part of the standard-of-care in myeloma, and new alkylators are coming to the market.

Keywords: alkylator; myeloma; melflufen; melphalan; bendamustine; cyclophosphamide

\section{Introduction}

Before alkylators, no drugs could alleviate the sufferings of multiple myeloma (MM) patients, but not for lack of trying. Leeches, steel, quinine, urethane rhubarb and orange peel were all tried, but not to much avail [1]. Alkylators constituted the first effective weapon in myeloma treatment and its use evolved through being the mainstay of handling myeloma patients for decades, to today, being an agent to combine with several other agents with different mechanisms of action in the armamentarium of a myeloma doctor.

Alkylators, in the form of "mustard gas", were first used by the German army in World War I, and, already in 1919, they were known to be suppressors of hematopoiesis [2], leading to mustine being the first chemotherapy used for patients with different forms of leukemia and lymphoma [3]. The drugs' mechanism is to add an alkyl group to DNA, causing linking between the two strands, inhibiting DNA and RNA synthesis and, thus, leading to cell death, preferentially in highly proliferative cells (Figure 1).

Melphalan was first synthesized in 1953 as a derivative of nitrogen mustard [4], eventually leading to the first documentation of clinical benefit in 3 of $6 \mathrm{MM}$ patients [5]. A decade later, the benefits of the combination of melphalan with prednisolone (MP) were demonstrated in a fairly large, randomized trial of 183 participants [6], establishing MP as a standard regimen for the rest of the century. The regimen is still in use in combination with other drugs.

The next big leap in myeloma treatment was to use high doses of melphalan, in the context of autologous stem cell transplant. After the first positive report in 1983 [7], several studies accumulated on the benefit of what became known as high-dose-melphalan with autologous stem cell transplant (HDM-ASCT), and, after a large, randomized study published in 1996 [8], it became established as the standard-of-care for young newly diagnosed 
myeloma patients. Over the years, several other alkylating drugs and other chemotherapeutics have been tested and used, including cyclophosphamide, carmustine, lomustine, bendamustine, cisplatin, vincristine and doxorubicin, also in the context of allogeneic stem cell transplantation [9]. One of the more noteworthy attempts was the VTD-PACE (bortezomib, thalidomide, dexamethasone, cisplatin, doxorubicin, cyclophosphamide and etoposide) regimen for induction and consolidation before transplant, in the total therapy 3 study [10], showing near-complete remission and 2-year survival rates in more than $80 \%$ of the patients. The regimen is toxic, but VTD-PACE and similar regimens are still being used occasionally for refractory patients at some centers [11].

\section{Alkylating agent Guanine}

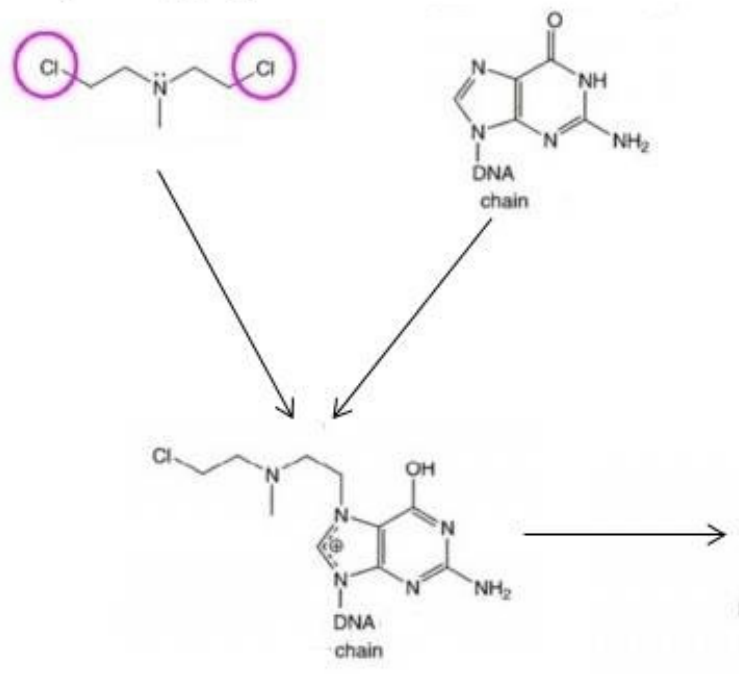

Alkylated guanine

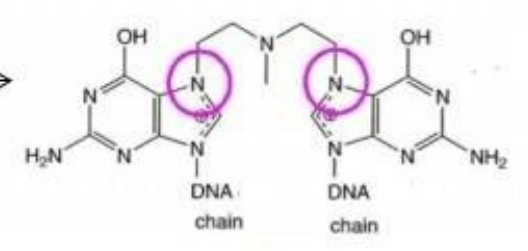

Crosslinking
Intra-strand crosslinking

Inter-strand crosslinking

Figure 1. Mechanism of action of alkylating agents. Alkylation of guanine may cause the excision or the opening of the guanine ring, thus interfering in base repairing. Bifunctional alkylating agents also cause intra and inter-strand crosslinking. Cross-linking interferes both with transcription and replication.

\section{Current Use of "Old" Alkylating Agents}

\subsection{Current Combinations with Melphalan}

Therapy with melphalan plus prednisone (MP) was the standard of care for patients with newly diagnosed MM for almost 40 years $[6,12]$ and when alternative combinations were developed as induction therapy for individuals eligible for high-dose melphalan therapy with hematopoietic stem-cell transplantation $[8,13]$, it remained the standard of care for elderly or unfit patients. Several combinations have built over the MP backbone. Preclinical studies proved that the proteasome inhibitor bortezomib sensitized melphalansensitive and melphalan-resistant myeloma cell lines to melphalan and down-regulated 
cellular responses to genotoxic stress [14,15]. The combination of bortezomib with MP was the first approved indication for bortezomib in the MM front-line setting [16]. Long-term follow-up of patients treated with MP plus bortezomib (MPV) showed unprecedented progression-free (PFS) and overall survival (OS) rates in newly diagnosed non-transplant candidate MM patients, with median durations of almost 2 and 5 years, respectively $[17,18]$. In the same period, the combination of thalidomide plus MP (MPT) was also compared with MP in six clinical trials [19-23], leading to a meta-analysis showing clear benefit and, thereafter, to the approval of the MPT regimen in the front-line setting [24]. PFS was 20.3 months and OS was 39.3 months. However, MPT proved inferior to the more convenient alkylator-free combination of lenalidomide and dexamethasone (Ld) [25] and, today, it is not used when other options are available. Other MP combinations have also been tried. MP plus lenalidomide was associated with a high rate of severe neutropenia [26] and did not provide a clear benefit over Ld [27] or MPT [28], and MP plus carfilzomib could not prove any significant benefit over MP plus bortezomib [29].

Standard dose melphalan, in combination, is typically used in a limited duration schedule up to 12 to 18 months. Subsequent evidence favored continuous rather than limited duration therapy [30], but the original MPV schedule using bi-weekly intravenous bortezomib was associated with a high incidence of peripheral neuropathy, leading to early bortezomib discontinuation in up to $30 \%$ of patients [16]. Several trials [31,32] successfully explored less intensive initial bortezomib dosing to reduce toxicity and to allow some modality of bortezomib maintenance; however, such dose modifications were not associated with major improvements in terms of efficacy over the original MPV schedules. Finally, the phase 3 randomized trial (ALCYONE) compared 12 months of MPV alone with MPV plus daratumumab (D-VMP) for 12 months followed by daratumumab maintenance in patients with newly diagnosed myeloma who were ineligible for high-dose therapy [33]. Its first prespecified interim analysis, after a median follow-up of 16.5 months, showed an 18 -month PFS rate of $71.6 \%$ in the daratumumab group, in contrast with $50.2 \%$ in the control group. The hazard ratio for disease progression or death was 0.50 ( $95 \%$ confidence interval 0.38 to $0.65 ; p<0.001)$. The benefit of the D-VMP combination was also observed in terms of overall response rate $(90.9 \%$ in the daratumumab group, as compared with $73.9 \%$ in the control group; $p<0.001)$, complete response or better $(42.6 \%$ versus $24.4 \%$; $p<0.001)$ and in terms of negativity for minimal residual disease $(22.3 \%$ as compared with $6.2 \%$ at a threshold of 1 tumor cell per 105 white cells; $p<0.001$ ). A recently published update, at a median follow-up of 40 months, confirmed the PFS benefit for the D-VMP group (hazard ratio 0.42 [0.34-0.51]; $p<0.0001$ ), and also observed a significant benefit in OS with a hazard ratio for death of 0.60 (95\% CI 0.46-0.80; $p=0.0003)$. The KaplanMeier estimate of the 36-month rate of OS was 78\% (95\% CI 73-82) in the D-VMP group and 68\% (63-73) in the VMP group [34]. Despite a higher rate of grade 3 or 4 infections ( $23 \%$ in the daratumumab group and $15 \%$ in the control group) and the occurrence of daratumumab-associated infusion-related reactions in $27.7 \%$ of the patients, the overall safety profile of D-VMP was adequate and led to the approval of the combination for newly diagnosed MM patients who are not candidates to autologous SCT. D-VMP was the first approved combination that included daratumumab in this setting, and also the first approved treatment strategy that included daratumumab as maintenance therapy.

\subsection{Current Status of HDM}

After a large, randomized study comparing conventional chemotherapy and HDMASCT, transplant became the standard-of-care for patients fit enough to go through the procedure [8]. In this study, the conditioning was a combination of melphalan (140 mg per square meter) and total-body irradiation $(4 \times 8 \mathrm{~Gy})$. A later study demonstrated the benefit, both in terms of safety and OS, of a higher dose of melphalan (200 mg per square meter) without total-body irradiation [35], and this has since remained the standard dose in this setting [36]. One recent randomized trial has challenged HDM-ASCT following currently preferred induction treatment with both an immunomodulatory agent and a proteasome 
inhibitor [37]. The IFM2009 study included 700 patients randomized to either eight cycles of RVd (Revlimid, Velcade, dexamethasone) or three induction cycles, HDM-ASCT and two additional consolidation cycles. Lenalidomide maintenance was given in both arms for 13 cycles. PFS was increased in the transplant-arm $(47.3 \mathrm{~m}$ vs. $35.0 \mathrm{~m} ; p=0.0001)$, but even after extended follow-up [38], no differences in PFS2 or OS have been observed. However, 201 patients in the non-transplant arm received transplant at relapse. In this context, the NCCN guidelines, despite calling ASCT the "preferred option", consider delayed transplant (at relapse) "appropriate as well" [39]. The use of HDM-ASCT, however, is still increasing in all regions of the world. In North America, the percentage of patients receiving HDM-ASCT, in 2015, was the highest in the world, and the highest ever (25.70\%). Among patients under the age of 70, the utilization rate in North America was 52.17\% [40]. In Europe, the respective numbers were $22.24 \%$ and $46.68 \%$, also the highest ever. In the rest of the world, the usage is lower, but increasing in all regions, with a global utilization rate in 2015 of $15.40 \%$. Although it has been argued that a MRD-driven approach, only forwarding MRD-positive patients after induction regimen to transplant [41], may reduce toxicity without compromising efficacy, such an approach has not been sustained in data from clinical trials so far.

A second transplant has been used in many countries as part of standard-of-care, either at first relapse, or as a consolidation of the first transplant, often referred to as tandem transplantation. Three recent first-line trials, carried out in Europe, performed single or tandem transplantation according to their local standards of care; while Italy and Germany performed tandem transplantation, patients in Spain and the Netherlands received a single procedure. A meta-analysis, so far unpublished, of these trials argued in favor of tandem transplantation [42]. In all, 909 patients were included in the analysis, 501 with single and 408 with tandem transplantation. OS at 120 months was $55 \%$ and $42 \%$ for tandem and single transplantation, respectively (HR 0.69; $p<0.001$ ). Similar results were achieved in the EMN02/HOVON95 study, in which a sub-study randomized patients after four induction cycles of bortezomib, cyclophosphamide and dexamethasone (VCD) to single or double transplant [43]. In this trial, there was also a significant benefit in terms of OS (HR 0.62; $p=0.022$ ) in the intention-to-treat population. Based on this, the ESMO guidelines recommend tandem transplantation to all patients who have received VCD as induction [36]. Another study (BMT CTN 0702) also randomized patients to single or tandem transplant but did not show any benefit regarding neither PFS nor OS [44]. In this study, patients had received different forms of induction treatment within a 4-12-month period, which makes the population less homogenous. In addition, $32 \%$ of the patients allocated to tandem transplant did not receive this treatment. A post-hoc analysis with longer follow up demonstrated a benefit in 6-year PFS in the as-treated group with tandem transplant vs. single transplant with $49.4 \%$ vs. $39.7 \%$; $p=0.01$ [45]. In both studies, the benefit was more pronounced in the high-risk population. Current ESMO guidelines propose tandem transplantation in patients with high-risk cytogenetic features [36], and the NCCN guidelines state that it should be considered for all patients who are candidates for HDM-SCT [39].

If a transplant is performed front-line, a second transplant at relapse can be considered, and has been commonly used in many countries. Two randomized trials have been performed to evaluate transplant at first relapse. The British Myeloma X trial randomized patients after induction with bortezomib, doxorubicin and dexamethasone (PAD) to a salvage transplant or to weekly oral cyclophosphamide for 12 weeks [46], and demonstrated an OS benefit of 67 vs. 52 months ( $p=0.022$ ). However, the control arm is not relevant to the relapse treatment of today. The other trial, the German ReLApsE trial, randomized patients to either Rd continuously or to Rd induction, transplant and lenalidomide maintenance, and showed no difference in progression-free or OS [47]. The panel consensus of both the ESMO and NCCN guidelines still states that salvage transplant may be considered in patients depending on the time from the preceding transplant; for instance, 36 months. It is 
likely that this should be given as an addition to the best relapse treatment available and not as an alternative.

High dose therapy is associated with significant morbidity, prolonged recovery time in a proportion of patients, and increased risk of secondary malignancies [48]. Samur et al. recently presented evidence of a significant increase in mutational burden in myeloma cells at relapse after high-dose-melphalan [49]. Consequently, as front-line induction treatment continues to improve, new studies will continue to challenge the paradigm of transplant with alternative options, including use of new immunotherapeutic agents, and the use of SCT depending on MRD status.

\subsection{Current Use of Cyclophosphamide}

The alkylating agent cyclophosphamide has been used as a second option to melphalan in the treatment of MM for decades. Cyclophosphamide is known to be less myelotoxic than melphalan and does not require dose adjustment in cases of renal insufficiency [50]; consequently, it may present a favourable safety profile compared to melphalan in frail individuals or patients with an impaired renal function. Cyclophosphamide is reported to have therapeutic effects at a wide range of doses, both by oral and intravenous routes [51,52]. Low doses of oral cyclophosphamide, often $50 \mathrm{mg}$ daily or $100 \mathrm{mg}$ every other day, have been extensively used in combination with corticoids for advanced disease in frail and elderly patients unable to tolerate more toxic combinations. A phase 3 trial compared carfilzomib monotherapy at $27 \mathrm{mg} / \mathrm{m}^{2}$ versus corticoids with or without low dose cyclophosphamide in patients who had received at least three prior treatments for MM and were refractory to their most recent therapy [53]. Ninety-five percent of patients in the control arm received the combination of a corticoid and cyclophosphamide. Although the overall response rate was superior for carfilzomib $(19.1 \%$ vs $11.4 \%)$, no differences were found in terms of progression-free or OS (3.3-3.7 and 10 months, respectively).

In the front-line setting, induction treatment with bortezomib, cyclophosphamide and dexamethasone (VCD or CyBorD) appears to be less effective than standard combinations of bortezomib with thalidomide or lenalidomide and dexamethasone $[54,55]$ and does not appear to add to the combination of bortezomib and dexamethasone alone [56]. However, due to the adverse toxicity profile of thalidomide and the unavailability of lenalidomide in certain countries, VCD is still an option in some centers [57,58], and is also a second option recommendation in several guidelines [36,39]. On the other hand, the addition of cyclophosphamide does not appear to add any benefit to the combination of an immunomodulatory drug, bortezomib and dexamethasone as front-line induction [59], or to lenalidomide and dexamethasone in the non-transplant setting [27]. The benefit of the addition of cyclophosphamide to carfilzomib and dexamethasone is also uncertain either in the front-line setting [60] or in relapsed and refractory MM patients [61], although in this later communication, lenalidomide-refractory patients appeared to benefit from the addition of cyclophosphamide to the proteasome inhibitor.

While the alkylating effect is predominant when cyclophosphamide is used at high doses, more recent studies have observed that cyclophosphamide at lower doses, also described as metronomic dosing, has significant immunomodulatory activity [62,63]. Although there is no clear borderline between low and high doses, new roles for the metronomic use of cyclophosphamide are being explored in the context of immune-mediated therapies, particularly immunomodulating agents. Weekly doses of cyclophosphamide can be safely added to the standard doses of lenalidomide and dexamethasone in relapsed/refractory myeloma [64,65]. Either $600 \mathrm{mg}$ cyclophosphamide flat dose on days 1 and 8 [64], or $300 \mathrm{mg} / \mathrm{m}^{2}$ on days 1,8 , and 15 [65], of a 28-day cycle, presented a manageable hematologic toxicity, providing overall response rates of 81 and $94 \%$, respectively, and a PFS projected over 2 years and of 16 months, although no large trial has been performed to confirm such findings. More interestingly, the REPEAT study, including 82 patients, was developed to test the hypothesis that the addition of low-dose metronomic oral cyclophosphamide to lenalidomide could induce a synergistic immunomodulatory effect [66]. The 
final dose of $25 \mathrm{mg}$ lenalidomide on days 1 to 21 , combined with continuous cyclophosphamide $50 \mathrm{mg} / \mathrm{d}$ and prednisone $20 \mathrm{mg} / \mathrm{d}$, showed an overall response rate of $67 \%$ and a median PFS and OS of 12.1 and 29.0 months, respectively, which are promising results considering that all 82 patients in the trial were lenalidomide refractory and $66 \%$ were also bortezomib refractory. Such results are comparable to the results of the two previous studies in which a less refractory population was included, and even comparable with the results of cyclophosphamide with lenalidomide and dexamethasone in the front-line setting, although the results have not been reproduced by other groups. The findings of the REPEAT trial may point out major differences in the immune effect of cyclophosphamide at different schedules and doses. The observation that the immunomodulatory properties of lenalidomide can be restored despite a clinical lenalidomide-refractory status can have implications for the development of future combination therapies. The mechanisms of such immunologic effects are far from being elucidated yet [67], but continuous low-dose cyclophosphamide appears to enhance anti-tumor immunity, via the depletion of regulatory T-cells, more efficiently than higher pulsed doses [68].

Similar immune-activating effects are likely to happen in combination with pomalidomide -dexamethasone. The first reported phase $1 / 2$ trial to explore the combination [69] considered pomalidomide up to $2.5 \mathrm{mg}$ /day as the maximum tolerated dose in combination with cyclophosphamide at $50 \mathrm{mg}$ and prednisone at $50 \mathrm{mg}$ every other day. The combination was given for six 28-day cycles, and then patients continued with pomalidomide and prednisone alone. All 69 patients had been exposed to lenalidomide and a third of them were refractory. The overall response rate was $51 \%$ (three patients, $5 \%$, achieved a complete response) and the PFS was 10.4 months. Similarly to lenalidomide and cyclophosphamide combinations, toxicity was mainly hematologic but manageable (basically neutropenia, grade 3 or higher, in $52 \%$ of patients) and the combination was considered to be safe. Other authors [70,71] have reported data for standard doses of pomalidomide at $4 \mathrm{mg}$ on 21 out of 28 days, and weekly $40 \mathrm{mg}$ doses of dexamethasone, in combination with pulsed cyclophosphamide at a $300 \mathrm{mg}$ or $400 \mathrm{mg}$ dose, with a similar hematological toxicity (20-30\% grade 3-4 neutropenia) and a 60 to $76 \%$ overall response rate. However, PFS was 7 months only in a mostly lenalidomide refractory population. In all, the results suggest a likely benefit for the addition of cyclophosphamide to pomalidomide alone. The only formal comparison was made in a randomized, multicenter phase 2 trial [72]. Following a dose escalation phase 1 cohort, lenalidomide refractory myeloma patients who had received $>2$ prior therapies were randomized to receive standard doses of pomalidomide and weekly dexamethasone in 28-day cycles (34 patients) or pomalidomide and dexamethasone with an additional $400 \mathrm{mg}$ cyclophosphamide orally on days 1,8 , and 15 (36 patients). The overall response rate was significantly superior $(p=0.035)$ for the combination with cyclophosphamide (65\%) $(95 \%$ confidence interval [CI], 49-81\%) compared to the control arm (39\%) $(95 \%$ CI, 23-55\%); median PFS was not significantly different between arms, although it tended to be higher in the cyclophosphamide arm, 9.5 months (95\% CI, 4.6-14) versus 4.4 (95\% CI, 2.3-5.7). Toxicity was manageable in both arms. The results appear to be only slightly inferior to those reported for the bortezomib, pomalidomide and dexamethasone combination in the OPTIMISMM trial [73] when taking into account that the study included a relevant proportion of patients who were also refractory to proteasome inhibitors ( $75 \%$ refractory to bortezomib and $41 \%$ to carfilzomib), who were not included in OPTIMISMM. Weekly oral cyclophosphamide at $300 \mathrm{mg}$ flat dose in addition to standard pomalidomide and dexamethasone was evaluated in less refractory patients in another nonrandomized, multicenter, phase 2 trial [74]. Patients treated front-line with lenalidomide-bortezomib-dexamethasone with or without stem-cell transplantation followed by lenalidomide maintenance were included at first relapse after discontinuation of lenalidomide maintenance; consequently, no patient was lenalidomide refractory. Responses were obtained in 82/97 (85\%) patients evaluated, with only $1(1 \%)$ obtaining a complete remission. The 34-month PFS must be interpreted cautiously, taking into consideration that patients who had not received an SCT front-line received SCT after five cycles of pomalidomide, dexamethasone and cyclophos- 
phamide. The addition of cyclophosphamide to patients presenting a suboptimal response to pomalidomide and dexamethasone has also been evaluated in the PERSPECTIVE phase 2 trial [75]. Patients on treatment with standard pomalidomide and dexamethasone, after at least two prior treatment lines including bortezomib and lenalidomide, were considered for the addition of cyclophosphamide $500 \mathrm{mg} / \mathrm{m}^{2}$ intravenously on days 1 and 15 if they presented disease progression or achieved less than a partial remission after three treatment cycles. Cyclophosphamide was given for a maximum of 12 cycles. Thirty-six patients were treated; of those progressing on pomalidomide and dexamethasone, only $25 \%$ (4 out of 16 ) obtained a partial or very good response. Of the remaining 20 patients who had presented stable disease or minor response to pomalidomide and dexamethasone alone, $33 \%$ and $80 \%$, respectively, upgraded to partial response or better. Only recently, a single-center phase 2 study has reported results for the continuous use of $50 \mathrm{mg}$ cyclophosphamide (days 1-21 of a 28 day cycle) in combination with standard doses of pomalidomide and dexamethasone in 33 lenalidomide refractory patients, $55 \%$ of whom were also refractory to a proteasome inhibitor [76]. The overall response rate was $73 \%$ and median progression-free and OSs were 13 months and 57 months, respectively. Based on such small trials, the addition of metronomic cyclophosphamide to pomalidomide and dexamethasone appears to improve the results of pomalidomide and dexamethasone alone without much safety compromise, although the overall benefit is difficult to compare with approved alternatives, particularly bortezomib, pomalidomide and dexamethasone. On the other hand, in certain settings, the combination may be cost-effective in comparison with the newly approved combinations of pomalidomide and dexamethasone with monoclonal antibodies [77-79].

Low-dose cyclophosphamide is a well-tolerated oral option, which may be useful in heavily treated older patients, when the therapeutic objective is restricted to symptomatic control and preservation of quality of life. Within modern myeloma therapy, the role of metronomic cyclophosphamide is likely to develop further despite the mechanisms underpinning its apparent synergism with immunomodulatory agents remaining insufficiently characterized, and its benefit in combination with monoclonal antibodies and new immunotherapy including cellular therapies still being unknown. A phase 2 trial evaluating daratumumab with cyclophosphamide, dexamethasone and pomalidomide is already ongoing [80]. Several important considerations, including best cyclophosphamide dosing and schedule, optimal partners, and best settings, remain to be elucidated.

\subsection{Current Use of Bendamustine}

The history of bendamustine is unusual. The drug was developed in East Germany behind the iron curtain, and was used to treat both lymphoma, lung cancer and myeloma in the 1970s, alas with few published and validated studies. Biochemically, it has some additional features compared to other alkylators, including a benzimidazole ring with antimetabolite-like properties [81]. It does cause DNA breaks like other alkylators [82], but, in addition, activates a base excision DNA repair pathway which is not seen with other drugs such as cyclophosphamide and melphalan. While other alkylating agents show a large degree of sensitivity overlap when tested in tumor lines, bendamustine displays unique non-cross-resistant features [83]. Bendamustine has established indications in the treatment of Cold Agglutinin Disease [84], Waldenströms macroglobulinemia [85], Hairy Cell Leukemia [86], Chronic Lymphocytic Leukemia [87], Mantle Cell Lymphoma [88], Follicular Lymphoma [89] and Marginal Zone Lymphoma [90]. It is also on the WHO list of essential medicines (https:/ / apps.who.int/iris/handle/10665/325771, accessed on 18 May 2021). However, due to the scarcity of phase- 3 trials and a very crowded field of new treatments, its use in MM is marginal. The new ESMO guidelines do not mention bendamustine as an option for relapsed/refractory myeloma [36].

The pivotal trial for bendamustine in myeloma, which led to the still existing marketing approval in newly diagnosed myeloma, was a randomized trial comparing Bendamustineprednisolone (BP) with the standard-of-care at that time, melphalan-prednisolone (MP) [91]. $\mathrm{BP}$ demonstrated a higher rate of complete response (32 vs. $13 \% ; p=0.007$ ), a longer time 
to treatment failure, a later primary endpoint of the study (14 vs. 10 months; $p<0.02$ ), and a significantly improved quality-of-life in several dimensions. This is the only example in myeloma where one alkylating agent proved superior to another in a head-to-head trial, although OS did not differ. In the same period, MP was improved by the addition of bortezomib or thalidomide (see Section 2.1), which both increased OS compared to MP alone. Since both bortezomib and thalidomide had significant neuropathy issues, $\mathrm{BP}$ was approved for newly diagnosed myeloma with neuropathy, precluding the use of bortezomib and thalidomide, and this is still the only approval for bendamustine in myeloma.

No randomized phase-3-trials with bendamustine have been performed in the relapsed/refractory myeloma setting. The lack of randomized trials is partly caused by prolonged legal discussions of patents and ownership. However, the belief in the drug's efficacy has led to a number of phase- 1 and phase- 2 trials (Table 1 ) that have combined bendamustine with other established active agents against myeloma. With the large gap that exists between approval of regimens and national reimbursement of the novel regimens in most countries, the fact that bendamustine is now generic creates the opportunity to use these combinations when other combinations are not available.

Table 1. Combination studies using bendamustine in the relapsed/refractory multiple myeloma setting.

\begin{tabular}{|c|c|c|c|c|c|c|}
\hline Combination & $\begin{array}{l}\text { Previous Lines } \\
\text { (Median) }\end{array}$ & $N$ & Dose of Study (a) & ORR & PFS & Reference \\
\hline Thalidomide-Prednisolone & 1 & 28 & $\begin{array}{c}60 \mathrm{mg} / \mathrm{m}^{2} \text { day } 1,8,15 \\
\text { (of } 28)\end{array}$ & $86 \%$ & $11 \mathrm{~m}$ & Pönisch BJH 2008 [92] \\
\hline Thalidomide-Dexamethasone & $1(\mathrm{~b})$ & 9 & $\begin{array}{l}120 \text { mg day } 1 \\
\text { (of } 28)\end{array}$ & $55 \%$ & NR & Ramasamy BJH 2011 [93] \\
\hline Lenalidomide-Dexamethasone & 3 & 29 & $\begin{array}{c}75 \mathrm{mg} / \mathrm{m}^{2} \text { day } 1,2 \\
\text { (of } 28 \text { ) }\end{array}$ & $52 \%$ & $6.1 \mathrm{~m}$ & Lentzsch Blood 2012 [94] \\
\hline Bortezomib & 6 & 40 & $\begin{array}{c}90 \mathrm{mg} / \mathrm{m}^{2} \text { day } 1,4 \\
\text { (of } 28)\end{array}$ & $52 \%$ & $8.4 \mathrm{~m}$ & Berenson BJH 2013 [95] \\
\hline Lenalidomide-Dexamethasone & 2 & 21 & $\begin{array}{c}75 \mathrm{mg} / \mathrm{m}^{2} \text { day } 1,2 \\
\text { (of } 28 \text { ) }\end{array}$ & $76 \%$ & $48 \%$ at $18 \mathrm{~m}$ & Pönisch BJH 2013 [96] \\
\hline Bortezomib-Dexamethasone & $3(\mathrm{c})$ & 36 & $\begin{array}{c}60 \mathrm{mg} / \mathrm{m}^{2} \text { day } 1,2 \\
\text { (of } 21)\end{array}$ & $67 \%$ & $\begin{array}{c}10 \mathrm{~m}(\mathrm{eGFR} \\
15-59)\end{array}$ & Pönisch JCancResClinOnc 2013 [97] \\
\hline Bortezomib-Dexamethasone & 2 & 79 & $\begin{array}{c}70 \mathrm{mg} / \mathrm{m}^{2} \text { day } 1,4 \\
\text { (of } 28)\end{array}$ & $61 \%$ & $9.7 \mathrm{~m}$ & Ludwig Blood 2014 [98] \\
\hline Bortezomib-Dexamethasone & $1(\mathrm{~d})$ & 73 & $\begin{array}{c}70 \mathrm{mg} / \mathrm{m}^{2} \text { day } 1,8 \\
\text { (of } 28 \text { ) }\end{array}$ & $58 \%$ & $10.8 \mathrm{~m}$ & Rodon Haematologica 2015 [99] \\
\hline Thalidomide-Dexamethasone & 3 & 94 & $\begin{array}{c}60 \mathrm{mg} / \mathrm{m}^{2} \text { day } 1,8 \\
\text { (of } 28)\end{array}$ & $46 \%$ & $7.5 \mathrm{~m}$ & Schey BJH 2015 [100] \\
\hline Lenalidomide-Dexamethasone & 3 & & $\begin{array}{c}75 \mathrm{mg} / \mathrm{m}^{2} \text { day } 1,2 \\
\text { (of } 28)\end{array}$ & $49 \%$ & $11.8 \mathrm{~m}$ & Kumar AJH 2015 [101] \\
\hline Lenalidomide-Dexamethasone & 2 & 38 & $\begin{array}{c}40 \mathrm{mg} / \mathrm{m}^{2} \text { day } 1,2 \\
\text { (of } 28)\end{array}$ & $\begin{array}{c}48 \% \\
\text { (phase 2) }\end{array}$ & $10 \mathrm{~m}$ & Pozzi LeukLymph 2017 [102] \\
\hline Lenalidomide-Dexamethasone & 1 & 50 & $\begin{array}{c}75 \mathrm{mg} / \mathrm{m}^{2} \text { day } 1,2 \\
\text { (of } 28 \text { ) }\end{array}$ & $89 \%$ & $18.6 \mathrm{~m}$ & Mey BJH 2017 [103] \\
\hline Lenalidomide-Dexamethasone & 1 & 25 & $\begin{array}{c}75 \mathrm{mg} / \mathrm{m}^{2} \text { day } 1,2 \\
\text { (of } 28)\end{array}$ & $88 \%$ & $22 \mathrm{~m}$ & Beck JCancResClinOnc 2017 [104] \\
\hline Pomalidomide-Dexamethasone & 5 & 38 & $\begin{array}{c}120 \mathrm{mg} / \mathrm{m}^{2} \text { day } 1 \\
\text { (of } 28)\end{array}$ & $61 \%$ & $9.6 \mathrm{~m}$ & Sivaraj BCJ 2018 [105] \\
\hline Carfilzomib-Dexamethasone & 4 & 63 & $\begin{array}{c}70 \mathrm{mg} / \mathrm{m}^{2} \text { day } 1,8 \\
\text { (of } 28)\end{array}$ & $51 \%$ & $11.6 \mathrm{~m}$ & Gramatzki ASCO2018 Abstract 8019 [106] \\
\hline Thalidomide-Dexamethasone & 3.5 & 30 & $\begin{array}{c}60 \mathrm{mg} / \mathrm{m}^{2} \text { day } 1,8,15 \\
\text { (of } 28)\end{array}$ & $37 \%$ & $6.2 \mathrm{~m}$ (TTF) & Mian BJH 2019 [107] \\
\hline Ixazomib-Dexamethasone & 4 & 28 & $\begin{array}{c}80 \mathrm{mg} / \mathrm{m}^{2} \text { day } 1,2 \\
\text { (of } 28 \text { ) }\end{array}$ & $\begin{array}{c}61 \% \\
\text { (phase 2) }\end{array}$ & $5.2 \mathrm{~m}$ & Dhakal BCJ 2019 [108] \\
\hline
\end{tabular}

(a) MTD in dose escalation trials. (b) All patients in ESRD. (c) All patients eGFR $<60 \mathrm{~mL} / \mathrm{min}$. (d) All patients $>65$ years of age. 
As seen in Table 1, most combination studies in RRMM have been performed with thalidomide, lenalidomide or bortezomib. Today, lenalidomide has replaced thalidomide, and both bortezomib and lenalidomide are most commonly used in first line treatment, making combinations with these drugs less useful at relapse. Carfilzomib and pomalidomide are becoming the backbone of triplet combinations in the relapsed and refractory setting. Two triplet combinations with carfilzomib are approved, in combination with lenalidomidedex [109], which is less of an option as more patients are refractory to lenalidomide at relapse, as well as the newly approved combination with daratumumab [110]. Pomalidomide also has an approved combination with a first-line drug, bortezomib [73], but it is also approved with the monoclonal antibodies elotuzumab [79] and isatuximab [78]. Reimbursement issues make the use of these two triplet regimens difficult in many countries. In such cases, the use of triplets with the generic drug bendamustine may be considered as long as they prove efficacious and safe in phase 2 trials.

The combination with pomalidomide-dexamethasone was tested in a phase I/II dose escalation trial in patients who were pomalidomide naïve, refractory to full-dose lenalidomide and refractory to the last treatment [105]. The study included 38 patients, who, in addition to lenalidomide, had all received bortezomib, $82 \%$ ASCT and 32\% carfilzomib. The median previous number of lines was $5(3-8)$. Treatment with bendamustine was given at $120 \mathrm{mg} / \mathrm{m}^{2}$ at day 1 of 28 , for 12 cycles, Pd was continued until progression. The MTD was defined to be pomalidomide $3 \mathrm{mg}$ (days 1-21) and dexamethasone (40 mg weekly). Hematologic toxicities were prevalent but could be effectively managed; the majority of patients discontinued treatment due to disease progression or lack of response. Overall response rate was $61 \%$ and median PFS was 9.6 months, comparing very favorably to the pivotal MM-003 study (31\% and 4.0 months; [111]), with a similar patient population.

In another study, bendamustine was combined with carfilzomib and dexamethasone in a phase I/II trial in patients with at least two previous lines of treatment [106]. The study included 63 patients, where $75 \%$ had received ASCT, $87 \%$ bortezomib, and $86 \%$ immunomodulatory drugs. The median previous number of lines was 4 (2-9). Treatment with bendamustine was given at $70 \mathrm{mg} / \mathrm{m}^{2}$ at day 1 and 8 of 28 for 8 cycles, before carfilzomib-dex maintenance every 14 days was continued until progression. The MTD was defined to be carfilzomib $\left(27 \mathrm{mg} / \mathrm{m}^{2}\right.$ ) (two first days with $20 \mathrm{mg} / \mathrm{m}^{2}$ ) administered on days 1, 2, 8, 9, 15 and 16, with dexamethasone $(20 \mathrm{mg})$ administered on the same days plus days 22 and 23. In addition, in this study the hematological toxicity was manageable, and there were no new safety signals. The overall response rate was $51 \%$ and the median PFS was 11.6 months, with the PFS being higher than the Kd doublet with $56 \mathrm{mg} / \mathrm{m}^{2}$ in a slightly more treated population (55\%, 4.1 months) [112].

In situations where triplets are not an option, bendamustine can also be combined with dexamethasone alone. Data are not extensive, but in an Italian study of eight frail patients with a median of four previous lines, the patients were treated with bendamustine $(60 \mathrm{mg})$ on days 1,8 and 15, and dexamethasone $(20 \mathrm{mg})$ weekly [113]. All patients had been treated with bortezomib (75\% refractory) and lenalidomide (62.5\% refractory), but with a median age of 76, only one of the patients had received a transplant. The combination was safe and provided an overall response rate of $55 \%$ and a PFS of 9.1 months.

Bendamustine has also been tested in newly diagnosed myeloma as part of conditioning before autologous stem cell transplant, and in multi-drug combinations. Two studies have evaluated the addition of bendamustine to melphalan as conditioning before the first ASCT [114,115], and Martino et al. tested this combination as part of the second transplant in a tandem strategy [116]. Combinations with bortezomib-dexamethasone have also been tried in patients with newly diagnosed myeloma with or without transplant $[117,118]$. Bendamustine has also been explored in combination with carfilzomib in this population [119]. Bendamustine in combination with bortezomib or carfilzomib in the front-line setting does not appear to provide relevant improvements over already established combinations. Other regimens including lenalidomide and daratumumab are probably better for induction in 
newly diagnosed patients, and the potential benefit of adding bendamustine to melphalan as conditioning would need to be confirmed in phase- 3 studies.

In summary, bendamustine is a unique drug with non-overlapping resistance to other alkylators. Evidence for its benefit is hampered by a lack of phase-3 trials, but it remains an alternative option if other triplets with carfilzomib and pomalidomide are not available.

\section{Melflufen}

Melphalan flufenamide (melflufen) is a first-in-class peptide-drug conjugate that targets aminopeptidases and rapidly releases alkylating agents into tumor cells [120-123]. Melflufen is rapidly taken up by myeloma cells due to its high lipophilicity $[120,124]$. The drug is dependent on its immediate cleavage by peptidases, which unleashes its more hydrophilic alkylator payload that remains entrapped within the cell (Figure 2).

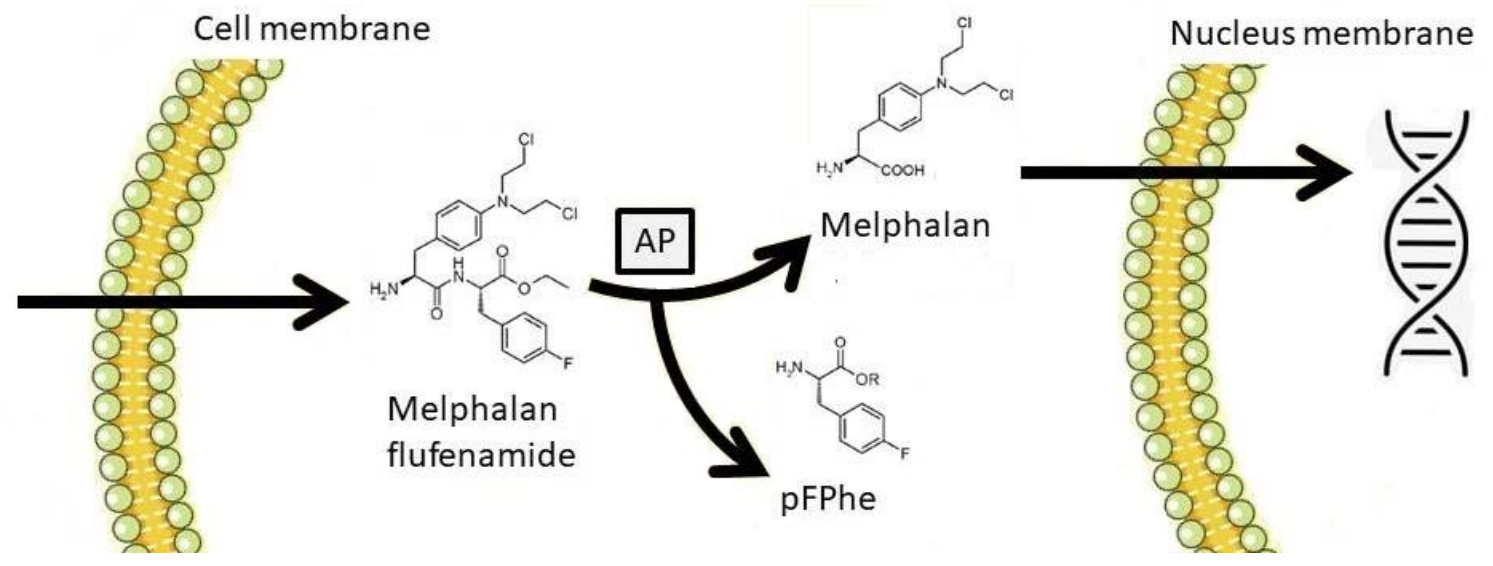

Figure 2. Melphalan flufenamide (melflufen) diffuses rapidly through the cellular membrane due to its lipophilic properties. Cytoplasmic aminopeptidases (AP) cleave melphalan from its peptide carrier ( $p F P h e$ ). The hydrophilic melphalan residue is trapped into the cell and exerts its alkylating effect in the DNA.

Peptidases are highly present in MM cells' cytoplasm [125-127]. Once inside the myeloma cell, melflufen rapidly induces irreversible DNA damage and apoptosis via an alkylator-like mechanism of cytotoxicity that is independent of p53 [124,128,129]. Melflufen is 50-fold more potent than melphalan in myeloma cells in vitro because the combined effects of its high lipophilicity and intracellular binding to aminopeptidases results in increased intracellular alkylator effect [120-123].

A Phase I/II study O-12-M1 [121] established an optimal cycle length of 28 days and a maximum tolerated flat dose of melflufen of $40 \mathrm{mg}$ administered as a single intravenous dose at day 1 of the cycle. Patients in the trial had received a median of four prior lines of therapy and $31 \%$ achieved at least a partial response. After a median follow-up of 28 months, the median PFS, duration of response (DOR) and OS were 5.7, 8.4 months and 20.7 months, respectively. Toxicity was basically hematological, including thrombocytopenia $(73 \%)$, neutropenia $(69 \%)$ and anemia $(64 \%)$. Pneumonia was the most common infectious complication (11\%). The HORIZON (OP-106) subsequent phase II trial was pivotal for establishing the efficacy of the drug [121]. The trial included 154 heavily pretreated and poor-risk patients with RRMM refractory to pomalidomide, an anti-CD38 $\mathrm{mAb}$, or both, who had exhausted most salvage therapy options. Patients had a median age of 64 years (range, 35-86), and 32\% had ISS stage III disease, 38\% had high-risk cytogenetics, and $32 \%$ had extramedullary disease. They had received a median of five prior lines of therapy (range, 2-12), 83\% had received prior alkylator therapy, $71 \%$ had triple-class refractory disease, and $69 \%$ had received $\geq 1$ prior autologous stem cell transplant. Among 125 efficacy-evaluable patients, the ORR was $29 \%$ (including 1 stringent complete response and 12 VGPR), thus confirming the efficacy observed in initial studies. The median PFS was 4.2 months and the median OS was 11.6 months; DOR was 5.5 months. Triple-class 
refractory patients and individuals with extramedullary disease achieved similar results to the overall population with an overall response rate of $24 \%$, a median duration of response of 7.5 and 5.1 months, respectively, and a median OS of 11.3 and 8.1 months, respectively. Melflufen and dexamethasone were generally safe and well tolerated. In the overall 154 safety-evaluable individuals, $97 \%$ of patients experienced a treatment-emergent $\mathrm{AE}$ and $85 \%$ experienced a grade 3 or 4 treatment-emergent $\mathrm{AE}$, but the incidence of nonhematologic AEs was low. Common grade $3 / 4$ toxicity consisted mostly of thrombocytopenia $(25 \% / 51 \%)$, neutropenia $(32 \% / 47 \%)$, and, less frequently, anemia $(42 \% /<1 \%)$. These encouraging results have triggered an ongoing registrational phase III trial comparing melflufen and dexamethasone with pomalidomide dexamethasone (OP-103) [130], which completed the recruitment of 450 individuals in 2020. The safety profile and mechanism of action of melflufen also suggest potentially active combinations. An ongoing phase I/II trial, ANCHOR (OP-104) [131], is currently evaluating the safety and efficacy of melflufen and dexamethasone in combination with daratumumab or bortezomib in patients who had received 1 to 4 prior lines of therapy. As recently communicated, 13 patients with a median of 3 prior lines of therapy, of whom $95 \%$ had been exposed to a proteasome inhibitor (range, 2-4), were treated with melflufen (six with $30 \mathrm{mg}$; seven with $40 \mathrm{mg}$ ) plus dexamethasone and bortezomib, with a median treatment duration of 9 months (range 1.4 to 29). ORR was $62 \%$, four patients achieved a VGPR and one a CR. In the other treatment arm, 33 patients, all of them lenalidomide and proteasome inhibitor refractory but not exposed to daratumumab, and with a median of 2 previous lines of therapy, received melflufen (6 with a 30-mg dose; 27 with a $40-\mathrm{mg}$ dose) in combination with daratumumab and dexamethasone. The ORR ( $\geq$ PR) was 73\% (including 2 CR and 10 VGPR), and the median PFS was 13 months. No dose-limiting toxicities were observed in any cohort and adverse events were consistent with those observed with melflufen and dexamethasone and those already known for daratumumab and bortezomib. No relevant treatment-related adverse events were observed other than hematological toxicity. Despite being an alkylating agent, melflufen does not appear to cause alopecia and the incidence of mucositis is low because of the selectivity of alkylation in cells with high expression of aminopeptidases.

In summary, melflufen has demonstrated durable responses in triple-refractory MM patients and a manageable safety profile. Treatment-related adverse events associated with melflufen and dexamethasone are primarily hematologic and rates of nonhematologic AEs are low. Based on this encouraging activity and acceptable safety profile, combination with proteasome inhibitors and anti-CD38 monoclonal antibodies may offer interesting results in less advanced patients. Melflufen was recently approved by the FDA.

\section{Current Standard of Care}

Today, the status of HDM-ASCT is still strong and is the recommended/preferred option in first-line transplant-eligible patients $[36,39]$. The role of tandem transplant is more controversial but is recommended for high-risk patients, for patients after treatment with VCD induction, and is an option for all patients. It is our opinion that salvage transplant should not be used as an alternative to the approved relapse triplets, but could be considered after a limited number of cycles of triplet therapy and always followed by continuous therapy.

In newly diagnosed transplant-ineligible patients, Dara-VMP is an adequate option if the lenalidomide-containing, alkylator-free triplets (VRd and Dara-Rd) [132,133] are not available.

Alkylator regimens at time of relapse are only supported by phase- 2 single arm trials, contrary to the randomized phase- 3 trials supporting carfilzomib- and pomalidomidebased triplets. Carfilzomib or pomalidomide, combined with an anti-CD38 antibody, have shown clear superiority over the doublets with dexamethasone $[78,110]$. In situations where the documented triplets are not available, we advocate considering the addition of cyclophosphamide or bendamustine, especially in patients with good bone marrow function and limited previous exposure to alkylators. 
In late line disease, several new options have emerged and recently been approved by the FDA and/or EMA. Amongst these is the alkylator melflufen, but also the nuclear transport inhibitor selinexor and the antibody-drug-conjugate drug belantamab mafodotin. The alkylator melflufen has the longest median PFS amongst these, but the differences are small, and the populations not entirely the same. As of today, they are all valid options, and the choice between them should be made based on availability, comorbidities, and patient choice. The most important adverse events are cytopenias for melflufen; cytopenias, fatigue and diarrhea for selinexor; and corneal events for belantamab. More information on these drugs in combination with other agents will be available in the near future.

Whether some clinical features, such as highly proliferative or extramedullary disease (EMD), should increase the inclination to administer alkylators is, as yet, unknown, although melflufen performed well in EMD patients [134]. Although some preclinical studies suggest biomarkers affecting response to alkylators [135], these data are so far too immature to impact treatment choice.

\section{Future Use of Alkylators}

Even though alkylators have been a mainstay in myeloma treatment for decades, their use is continuously being challenged due to their potential long-term toxicity. Two recent randomized studies compared transplant with a non-transplant approach in firstline treatment, but, in both cases, the transplant arm prevailed [37,43]. Still, the reduced quality-of-life in the period after transplant, as well as the increased mutational burden and increase in secondary malignancies seen after alkylator use, remains a concern. Efficacious immunotherapy, including chimeric-antibody-receptor T cells (CAR-Ts) and bispecific antibodies, have provided better results in terms of response rates and progression-free survival in later lines, and the possibility of including these agents as part of first-line treatments may again challenge HDM in first line $[136,137]$. Currently, several trials are being performed in which these agents are incorporated in first-line treatment in a design without HDM (e.g., NCT04196491, ClinicalTrials.gov).

Alkylating agents, as part of front-line induction treatment in transplant-ineligible patients, have been replaced by more active combinations, including both proteasome inhibitors, immunomodulating agents and monoclonal CD38 antibodies. Still, as long as most patients are not cured, the exposure to alkylators at some point throughout the disease will continue to be beneficial. The lack of comparative trials between alkylators makes it difficult to state with certainty that there are efficacy differences between the different drugs, but with the new delivery mechanism and the recent phase- 2 data, the novel alkylator melflufen is the most promising agent today. Phase 3 combination studies are underway, and will shed light on the benefits of melflufen in combination, first with pomalidomide [130], and next with daratumumab (NCT04649060, ClinicalTrials.gov).

Currently, many studies are being performed for patients with smouldering multiple myeloma. As of today, we do not see a place for alkylators in this setting. The concern regarding increased mutational burden is higher in these patients, and the aim should be to cure them without inflicting genetic damage.

\section{Conclusions}

For decades, alkylating agents, together with corticosteroids, have been the only efficacious drugs for the treatment of MM and, to date, they remain a cornerstone of MM treatment. Despite rising concern regarding induced DNA damage caused by this class of drugs, most patients with MM, in all parts of the world, will receive an alkylating agent in their disease course. The use of high-dose melphalan with stem cell transplant is still increasing in all global regions, and new alkylator-containing regimens have recently been approved by the FDA and the EMA. 
In addition, a novel alkylator is now about to enter the market. Melflufen has a distinct mechanism-of-action and becomes active only in peptidase-rich cells, leading to less off-target effects and higher potency towards myeloma cells. Phase 1 and 2-studies have been published, and results from the first phase- 3 trial are eagerly awaited.

Author Contributions: Conceptualization, F.S. and A.O.; writing—original draft preparation, F.S. and A.O.; writing - review and editing, F.S. and A.O.; project administration, F.S. All authors have read and agreed to the published version of the manuscript.

Funding: This research received no external funding.

Conflicts of Interest: F.S. has received honoraria, participated in advisory boards or received research grants from Amgen, Takeda, Janssen, SkyliteDX, Oncopeptides, Sanofi, Celgene and GSK. A.O. has received honoraria and participated in advisory boards for Amgen, BMS/Celgene, Sanofi, GSK and Janssen.

\section{References}

1. Kyle, R.A.; Rajkumar, S.V. Multiple myeloma. Blood 2008, 111, 2962-2972. [CrossRef] [PubMed]

2. Krumbhaar, E.B. Rôle of the Blood and the bone marrow in certain forms of gas poisoning: I. peripheral blood changes and their significance. J. Am. Med. Assoc. 1919, 72, 39-41. [CrossRef]

3. Gilman, A. The initial clinical trial of nitrogen mustard. Am. J. Surg. 1963, 105, 574-578. [CrossRef]

4. Bergel, F.; Stock, J. Cytotoxic $\alpha$ amino acids and peptides. Br. Emp. Cancer Campain 1953, 31, 6-7.

5. Blokhin, N.; Larionov, L.; Perevodchikova, N.; Chebotareva, L.; Merkulova, N. Clinical experiences with sarcolysin in neoplastic diseases. Ann. N. Y. Acad. Sci. 1958, 68, 1128-1132. [CrossRef]

6. Alexanian, R.; Haut, A.; Khan, A.U.; Lane, M.; McKelvey, E.M.; Migliore, P.J; Stuckey, W.J., Jr.; Wilson, H.E. Treatment for multiple myeloma. Combination chemotherapy with different melphalan dose regimens. JAMA 1969, 208, 1680-1685. [CrossRef]

7. McElwain, T.J.; Powles, R.L. High-dose intravenous melphalan for plasma-cell leukaemia and myeloma. Lancet 1983, 2, 822-824. [CrossRef]

8. $\quad$ Attal, M.; Harousseau, J.L.; Stoppa, A.M.; Sotto, J.J; Fuzibet, J.G.; Rossi, J.F.; Casassus, P.; Maisonneuve, H.; Facon, T.; Ifrah, N.; et al. A prospective, randomized trial of autologous bone marrow transplantation and chemotherapy in multiple myeloma. Intergroupe Francais du Myelome. N. Engl. J. Med. 1996, 335, 91-97. [CrossRef]

9. Gahrton, G.; Tura, S.; Flesch, M.; Gratwohl, A.; Gravett, P.; Lucarelli, G.; Michallet, M.; Reiffers, J.; Ringden, O.; van Lint, M.T.; et al. Bone marrow transplantation in multiple myeloma: Report from the European Cooperative Group for Bone Marrow Transplantation. Blood 1987, 69, 1262-1264. [CrossRef]

10. Barlogie, B.; Anaissie, E.; van Rhee, F.; Haessler, J.; Hollmig, K.; Pineda-Roman, M.; Cottler-Fox, M.; Mohiuddin, A.; Alsayed, Y.; Tricot, G.; et al. Incorporating bortezomib into upfront treatment for multiple myeloma: Early results of total therapy 3. Br. J. Haematol. 2007, 138, 176-185. [CrossRef] [PubMed]

11. Lakshman, A.; Singh, P.P; Rajkumar, S.V.; Dispenzieri, A.; Lacy, M.Q.; Gertz, M.A.; Buadi, F.K.; Dingli, D.; Hwa, Y.L.; Fonder, A.L.; et al. Efficacy of VDT PACE-like regimens in treatment of relapsed/refractory multiple myeloma. Am. J. Hematol. 2018, 93, 179-186. [CrossRef] [PubMed]

12. Kyle, R.A.; Rajkumar, S.V. Multiple myeloma. N. Engl. J. Med. 2004, 351, 1860-1873. [CrossRef] [PubMed]

13. Child, J.A.; Morgan, G.J.; Davies, F.E.; Owen, R.G.; Bell, S.E.; Hawkins, K.; Brown, J.; Drayson, M.T.; Selby, P.J.; Medical Research Council Adult Leukaemia Working, P. High-dose chemotherapy with hematopoietic stem-cell rescue for multiple myeloma. $N$. Engl. J. Med. 2003, 348, 1875-1883. [CrossRef]

14. Mitsiades, N.; Mitsiades, C.S.; Richardson, P.G.; Poulaki, V.; Tai, Y.T.; Chauhan, D.; Fanourakis, G.; Gu, X.; Bailey, C.; Joseph, M.; et al. The proteasome inhibitor PS-341 potentiates sensitivity of multiple myeloma cells to conventional chemotherapeutic agents: Therapeutic applications. Blood 2003, 101, 2377-2380. [CrossRef] [PubMed]

15. Ma, M.H.; Yang, H.H.; Parker, K.; Manyak, S.; Friedman, J.M.; Altamirano, C.; Wu, Z.Q.; Borad, M.J.; Frantzen, M.; Roussos, E.; et al. The proteasome inhibitor PS-341 markedly enhances sensitivity of multiple myeloma tumor cells to chemotherapeutic agents. Clin. Cancer Res. 2003, 9, 1136-1144.

16. San Miguel, J.F.; Schlag, R.; Khuageva, N.K.; Dimopoulos, M.A.; Shpilberg, O.; Kropff, M.; Spicka, I.; Petrucci, M.T.; Palumbo, A.; Samoilova, O.S.; et al. Bortezomib plus melphalan and prednisone for initial treatment of multiple myeloma. N. Engl. J. Med. 2008, 359, 906-917. [CrossRef]

17. Mateos, M.V.; Hernandez, J.M.; Hernandez, M.T.; Gutierrez, N.C.; Palomera, L.; Fuertes, M.; Garcia-Sanchez, P.; Lahuerta, J.J; de la Rubia, J.; Terol, M.J.; et al. Bortezomib plus melphalan and prednisone in elderly untreated patients with multiple myeloma: Updated time-to-events results and prognostic factors for time to progression. Haematologica 2008, 93, 560-565. [CrossRef]

18. San Miguel, J.F.; Schlag, R.; Khuageva, N.K.; Dimopoulos, M.A.; Shpilberg, O.; Kropff, M.; Spicka, I.; Petrucci, M.T.; Palumbo, A.; Samoilova, O.S.; et al. Persistent overall survival benefit and no increased risk of second malignancies with bortezomib-melphalanprednisone versus melphalan-prednisone in patients with previously untreated multiple myeloma. J. Clin. Oncol. 2013, 31, 448-455. [CrossRef] 
19. Palumbo, A.; Bringhen, S.; Caravita, T.; Merla, E.; Capparella, V.; Callea, V.; Cangialosi, C.; Grasso, M.; Rossini, F.; Galli, M.; et al. Oral melphalan and prednisone chemotherapy plus thalidomide compared with melphalan and prednisone alone in elderly patients with multiple myeloma: Randomised controlled trial. Lancet 2006, 367, 825-831. [CrossRef]

20. Facon, T.; Mary, J.Y.; Hulin, C.; Benboubker, L.; Attal, M.; Pegourie, B.; Renaud, M.; Harousseau, J.L.; Guillerm, G.; Chaleteix, C.; et al. Melphalan and prednisone plus thalidomide versus melphalan and prednisone alone or reduced-intensity autologous stem cell transplantation in elderly patients with multiple myeloma (IFM 99-06): A randomised trial. Lancet 2007, 370, 1209-1218. [CrossRef]

21. Wijermans, P.; Schaafsma, M.; Termorshuizen, F.; Ammerlaan, R.; Wittebol, S.; Sinnige, H.; Zweegman, S.; van Marwijk Kooy, M.; van der Griend, R.; Lokhorst, H.; et al. Phase III study of the value of thalidomide added to melphalan plus prednisone in elderly patients with newly diagnosed multiple myeloma: The HOVON 49 Study. J. Clin. Oncol. 2010, 28, 3160-3166. [CrossRef] [PubMed]

22. Waage, A.; Gimsing, P.; Fayers, P.; Abildgaard, N.; Ahlberg, L.; Bjorkstrand, B.; Carlson, K.; Dahl, I.M.; Forsberg, K.; Gulbrandsen, N.; et al. Melphalan and prednisone plus thalidomide or placebo in elderly patients with multiple myeloma. Blood 2010, 116, 1405-1412. [CrossRef]

23. Beksac, M.; Haznedar, R.; Firatli-Tuglular, T.; Ozdogu, H.; Aydogdu, I.; Konuk, N.; Sucak, G.; Kaygusuz, I.; Karakus, S.; Kaya, E.; et al. Addition of thalidomide to oral melphalan/prednisone in patients with multiple myeloma not eligible for transplantation: Results of a randomized trial from the Turkish Myeloma Study Group. Eur. J. Haematol. 2011, 86, 16-22. [CrossRef]

24. Fayers, P.M.; Palumbo, A.; Hulin, C.; Waage, A.; Wijermans, P.; Beksac, M.; Bringhen, S.; Mary, J.Y.; Gimsing, P.; Termorshuizen, F.; et al Thalidomide for previously untreated elderly patients with multiple myeloma: Meta-analysis of 1685 individual patient data from 6 randomized clinical trials. Blood 2011, 118, 1239-1247. [CrossRef] [PubMed]

25. Benboubker, L.; Dimopoulos, M.A.; Dispenzieri, A.; Catalano, J.; Belch, A.R.; Cavo, M.; Pinto, A.; Weisel, K.; Ludwig, H.; Bahlis, N.; et al . Lenalidomide and dexamethasone in transplant-ineligible patients with myeloma. N. Engl. J. Med. 2014, 371, 906-917. [CrossRef] [PubMed]

26. Palumbo, A.; Hajek, R.; Delforge, M.; Kropff, M.; Petrucci, M.T.; Catalano, J.; Gisslinger, H.; Wiktor-Jedrzejczak, W.; Zodelava, M.; Weisel, K.; et al. Continuous lenalidomide treatment for newly diagnosed multiple myeloma. N. Engl. J. Med. 2012, 366, 1759-1769. [CrossRef]

27. Magarotto, V.; Bringhen, S.; Offidani, M.; Benevolo, G.; Patriarca, F.; Mina, R.; Falcone, A.P.; De Paoli, L.; Pietrantuono, G.; Gentili, S.; et al. Triplet vs doublet lenalidomide-containing regimens for the treatment of elderly patients with newly diagnosed multiple myeloma. Blood 2016, 127, 1102-1108. [CrossRef]

28. Zweegman, S.; van der Holt, B.; Mellqvist, U.H.; Salomo, M.; Bos, G.M.; Levin, M.D.; Visser-Wisselaar, H.; Hansson, M.; van der Velden, A.W.; Deenik, W.; et al. Melphalan, prednisone, and lenalidomide versus melphalan, prednisone, and thalidomide in untreated multiple myeloma. Blood 2016, 127, 1109-1116. [CrossRef] [PubMed]

29. Facon, T.; Lee, J.H.; Moreau, P.; Niesvizky, R.; Dimopoulos, M.; Hajek, R.; Pour, L.; Jurczyszyn, A.; Qiu, L.; Klippel, Z.; et al. Carfilzomib or bortezomib with melphalan-prednisone for transplant-ineligible patients with newly diagnosed multiple myeloma. Blood 2019, 133, 1953-1963. [CrossRef]

30. Palumbo, A.; Gay, F.; Cavallo, F.; Di Raimondo, F.; Larocca, A.; Hardan, I.; Nagler, A.; Petrucci, M.T.; Hajek, R.; Pezzatti, S.; et al. Continuous Therapy Versus Fixed Duration of Therapy in Patients with Newly Diagnosed Multiple Myeloma. J. Clin. Oncol. 2015, 33, 3459-3466. [CrossRef]

31. Palumbo, A.; Bringhen, S.; Larocca, A.; Rossi, D.; Di Raimondo, F.; Magarotto, V.; Patriarca, F.; Levi, A.; Benevolo, G.; Vincelli, I.D.; et al. Bortezomib-melphalan-prednisone-thalidomide followed by maintenance with bortezomib-thalidomide compared with bortezomib-melphalan-prednisone for initial treatment of multiple myeloma: Updated follow-up and improved survival. J. Clin. Oncol. 2014, 32, 634-640. [CrossRef]

32. Mateos, M.V.; Oriol, A.; Martinez-Lopez, J.; Gutierrez, N.; Teruel, A.I.; de Paz, R.; Garcia-Larana, J.; Bengoechea, E.; Martin, A.; Mediavilla, J.D.; et al. Bortezomib, melphalan, and prednisone versus bortezomib, thalidomide, and prednisone as induction therapy followed by maintenance treatment with bortezomib and thalidomide versus bortezomib and prednisone in elderly patients with untreated multiple myeloma: A randomised trial. Lancet Oncol. 2010, 11, 934-941. [CrossRef]

33. Mateos, M.V.; Dimopoulos, M.A.; Cavo, M.; Suzuki, K.; Jakubowiak, A.; Knop, S.; Doyen, C.; Lucio, P.; Nagy, Z.; Kaplan, P.; et al. Daratumumab plus Bortezomib, Melphalan, and Prednisone for Untreated Myeloma. N. Engl. J. Med. 2018, 378, 518-528. [CrossRef]

34. Mateos, M.V.; Cavo, M.; Blade, J.; Dimopoulos, M.A.; Suzuki, K.; Jakubowiak, A.; Knop, S.; Doyen, C.; Lucio, P.; Nagy, Z.; et al. Overall survival with daratumumab, bortezomib, melphalan, and prednisone in newly diagnosed multiple myeloma (ALCYONE): A randomised, open-label, phase 3 trial. Lancet 2020, 395, 132-141. [CrossRef]

35. Moreau, P.; Facon, T.; Attal, M.; Hulin, C.; Michallet, M.; Maloisel, F.; Sotto, J.J.; Guilhot, F.; Marit, G.; Doyen, C.; et al Comparison of $200 \mathrm{mg} / \mathrm{m}^{2}$ melphalan and $8 \mathrm{~Gy}$ total body irradiation plus $140 \mathrm{mg} / \mathrm{m}^{2}$ melphalan as conditioning regimens for peripheral blood stem cell transplantation in patients with newly diagnosed multiple myeloma: Final analysis of the Intergroupe Francophone du Myelome 9502 randomized trial. Blood 2002, 99, 731-735. [CrossRef] [PubMed]

36. Dimopoulos, M.A.; Moreau, P.; Terpos, E.; Mateos, M.V.; Zweegman, S.; Cook, G.; Delforge, M.; Hajek, R.; Schjesvold, F.; Cavo, M.; et al. Multiple myeloma: EHA-ESMO Clinical Practice Guidelines for diagnosis, treatment and follow-up(dagger). Ann. Oncol. 2021, 32, 309-322. [CrossRef] [PubMed] 
37. Attal, M.; Lauwers-Cances, V.; Hulin, C.; Leleu, X.; Caillot, D.; Escoffre, M.; Arnulf, B.; Macro, M.; Belhadj, K.; Garderet, L.; et al. Lenalidomide, Bortezomib, and Dexamethasone with Transplantation for Myeloma. N. Engl. J. Med. 2017, 376, 1311-1320. [CrossRef] [PubMed]

38. Perrot, A.; Lauwers-Cances, V.; Cazaubiel, T.; Facon, T.; Caillot, D.; Clement-Filliatre, L.; Macro, M.; Decaux, O.; Belhadj, K.; Mohty, M.; et al. Early Versus Late Autologous Stem Cell Transplant in Newly Diagnosed Multiple Myeloma: Long-Term Follow-up Analysis of the IFM 2009 Trial. Blood 2020, 136, 39. [CrossRef]

39. Kumar, S.K.; Callander, N.S.; Adekola, K.; Anderson, L.; Baljevic, M.; Campagnaro, E.; Castillo, J.J.; Chandler, J.C.; Costello, C.; Efebera, Y.; et al. Multiple Myeloma, Version 3.2021, NCCN Clinical Practice Guidelines in Oncology. J. Natl. Compr. Cancer Netw. 2020, 18, 1685-1717. [CrossRef]

40. Cowan, A.J.; Baldomero, H.; Atsuta, Y.; Mikhael, J.; Aljurf, M.; Seber, A.; Greinix, H.; Koh, M.; Worel, N.; Libby, E.N.; et al. The Global State of Hematopoietic Cell Transplantation for Multiple Myeloma: An Analysis of the Worldwide Network of Blood and Marrow Transplantation Database and the Global Burden of Disease Study. Biol. Blood Marrow Transpl. 2020, 26, $2372-2377$. [CrossRef]

41. Kazandjian, D.; Mo, C.C.; Landgren, O.; Richardson, P.G. The role of high-dose melphalan with autologous stem-cell transplant in multiple myeloma: Is it time for a paradigm shift? Br. J. Haematol. 2020, 191, 692-703. [CrossRef] [PubMed]

42. Cavo, M.; Goldschmidt, H.; Rosinol, L.; Pantani, L.; Zweegman, S.; Salwender, H.J.; Lahuerta, J.J.; Lokhorst, H.M.; Petrucci, M.T.; Blau, I.; et al. Double Vs Single Autologous Stem Cell Transplantation for Newly Diagnosed Multiple Myeloma: Long-Term Follow-up (10-Years) Analysis of Randomized Phase 3 Studies. Blood 2018, 132, 124. [CrossRef]

43. Cavo, M.; Gay, F.; Beksac, M.; Pantani, L.; Petrucci, M.T.; Dimopoulos, M.A.; Dozza, L.; van der Holt, B.; Zweegman, S.; Oliva, S.; et al. Autologous haematopoietic stem-cell transplantation versus bortezomib-melphalan-prednisone, with or without bortezomiblenalidomide-dexamethasone consolidation therapy, and lenalidomide maintenance for newly diagnosed multiple myeloma (EMN02/HO95): A multicentre, randomised, open-label, phase 3 study. Lancet Haematol. 2020, 7, e456-e468. [CrossRef]

44. Stadtmauer, E.A.; Pasquini, M.C.; Blackwell, B.; Hari, P.; Bashey, A.; Devine, S.; Efebera, Y.; Ganguly, S.; Gasparetto, C.; Geller, N.; et al. Autologous Transplantation, Consolidation, and Maintenance Therapy in Multiple Myeloma: Results of the BMT CTN 0702 Trial. J. Clin. Oncol. 2019, 37, 589-597. [CrossRef]

45. Hari, P.; Pasquini, M.C.; Stadtmauer, E.A.; Fraser, R.; Fei, M.; Devine, S.M.; Efebera, Y.A.; Geller, N.; Horowitz, M.M.; Koreth, J.; et al. Long-term follow-up of BMT CTN 0702 (STaMINA) of postautologous hematopoietic cell transplantation (autoHCT) strategies in the upfront treatment of multiple myeloma (MM). J. Clin. Oncol. 2020, 38, 8506. [CrossRef]

46. Cook, G.; Ashcroft, A.J.; Cairns, D.A.; Williams, C.D.; Brown, J.M.; Cavenagh, J.D.; Snowden, J.A.; Parrish, C.; Yong, K.; Cavet, J.; et al. The effect of salvage autologous stem-cell transplantation on overall survival in patients with relapsed multiple myeloma (final results from BSBMT/UKMF Myeloma X Relapse [Intensive]): A randomised, open-label, phase 3 trial. Lancet Haematol. 2016, 3 , e340-e351. [CrossRef]

47. Goldschmidt, H.; Baertsch, M.A.; Schlenzka, J.; Becker, N.; Habermehl, C.; Hielscher, T.; Raab, M.S.; Hillengass, J.; Sauer, S.; Muller-Tidow, C.; et al. Salvage autologous transplant and lenalidomide maintenance vs. lenalidomide/dexamethasone for relapsed multiple myeloma: The randomized GMMG phase III trial ReLApsE. Leukemia 2020. [CrossRef] [PubMed]

48. Radivoyevitch, T.; Dean, R.M.; Shaw, B.E.; Brazauskas, R.; Tecca, H.R.; Molenaar, R.J.; Battiwalla, M.; Savani, B.N.; Flowers, M.E.D.; Cooke, K.R.; et al. Risk of acute myeloid leukemia and myelodysplastic syndrome after autotransplants for lymphomas and plasma cell myeloma. Leuk. Res. 2018, 74, 130-136. [CrossRef]

49. Samur, M.K.; Roncador, M.; Aktas-Samur, A.; Fulciniti, M.; Bazarbachi, A.H.; Szalat, R.; Shammas, M.A.; Sperling, A.S.; Richardson, P.G.; Magrangeas, F.; et al. High-Dose Melphalan Significantly Increases Mutational Burden in Multiple Myeloma Cells at Relapse: Results from a Randomized Study in Multiple Myeloma. Blood 2020, 136, 4-5. [CrossRef]

50. Song, M.K.; Chung, J.S.; Shin, H.J.; Moon, J.H.; Lee, J.J.; Yoon, S.S.; Kim, J.S.; Lee, J.O.; Do, Y.R.; Lee, H.S.; et al. Cyclophosphamidecontaining regimen (TCD) is superior to melphalan-containing regimen (MPT) in elderly multiple myeloma patients with renal impairment. Ann. Hematol. 2012, 91, 889-896. [CrossRef]

51. Kyle, R.A.; Jacobus, S.; Friedenberg, W.R.; Slabber, C.F.; Rajkumar, S.V.; Greipp, P.R. The treatment of multiple myeloma using vincristine, carmustine, melphalan, cyclophosphamide, and prednisone (VBMCP) alternating with high-dose cyclophosphamide and $\alpha(2) \beta$ interferon versus VBMCP: Results of a phase III Eastern Cooperative Oncology Group Study E5A93. Cancer 2009, 115, 2155-2164. [CrossRef]

52. Tabchi, S.; Nair, R.; Kunacheewa, C.; Patel, K.K.; Lee, H.C.; Thomas, S.K.; Amini, B.; Ahmed, S.; Mehta, R.S.; Bashir, Q.; et al. Retrospective Review of the Use of High-Dose Cyclophosphamide, Bortezomib, Doxorubicin, and Dexamethasone for the Treatment of Multiple Myeloma and Plasma Cell Leukemia. Clin. Lymphoma Myeloma Leuk. 2019, 19, 560-569. [CrossRef] [PubMed]

53. Hajek, R.; Masszi, T.; Petrucci, M.T.; Palumbo, A.; Rosinol, L.; Nagler, A.; Yong, K.L.; Oriol, A.; Minarik, J.; Pour, L.; et al. A randomized phase III study of carfilzomib vs low-dose corticosteroids with optional cyclophosphamide in relapsed and refractory multiple myeloma (FOCUS). Leukemia 2017, 31, 107-114. [CrossRef] [PubMed]

54. Cavo, M.; Pantani, L.; Pezzi, A.; Petrucci, M.T.; Patriarca, F.; Di Raimondo, F.; Marzocchi, G.; Galli, M.; Montefusco, V.; Zamagni, E.; et al. Bortezomib-thalidomide-dexamethasone (VTD) is superior to bortezomib-cyclophosphamide-dexamethasone (VCD) as induction therapy prior to autologous stem cell transplantation in multiple myeloma. Leukemia 2015, 29, 2429-2431. [CrossRef] [PubMed] 
55. Moreau, P.; Hulin, C.; Macro, M.; Caillot, D.; Chaleteix, C.; Roussel, M.; Garderet, L.; Royer, B.; Brechignac, S.; Tiab, M.; et al. VTD is superior to VCD prior to intensive therapy in multiple myeloma: Results of the prospective IFM2013-04 trial. Blood 2016, 127, 2569-2574. [CrossRef]

56. Figueiredo, A.; Atkins, H.; Mallick, R.; Kekre, N.; Kew, A.; McCurdy, A. Cyclophosphamide-bortezomib-dexamethasone compared with bortezomib-dexamethasone in transplantation-eligible patients with newly diagnosed multiple myeloma. Curr. Oncol. 2020, 27, e81-e85. [CrossRef]

57. Areethamsirikul, N.; Masih-Khan, E.; Chu, C.M.; Jimenez-Zepeda, V.; Reece, D.E.; Trudel, S.; Kukreti, V.; Tiedemann, R.; Chen, C. CyBorD induction therapy in clinical practice. Bone Marrow Transpl. 2015, 50, 375-379. [CrossRef]

58. Einsele, H.; Engelhardt, M.; Tapprich, C.; Muller, J.; Liebisch, P.; Langer, C.; Kropff, M.; Mugge, L.O.; Jung, W.; Wolf, H.H.; et al. Phase II study of bortezomib, cyclophosphamide and dexamethasone as induction therapy in multiple myeloma: DSMM XI trial. Br. J. Haematol. 2017, 179, 586-597. [CrossRef]

59. Kumar, S.; Flinn, I.; Richardson, P.G.; Hari, P.; Callander, N.; Noga, S.J.; Stewart, A.K.; Turturro, F.; Rifkin, R.; Wolf, J.; et al. Randomized, multicenter, phase 2 study (EVOLUTION) of combinations of bortezomib, dexamethasone, cyclophosphamide, and lenalidomide in previously untreated multiple myeloma. Blood 2012, 119, 4375-4382. [CrossRef] [PubMed]

60. Mina, R.; Bonello, F.; Petrucci, M.T.; Liberati, A.M.; Conticello, C.; Ballanti, S.; Musto, P.; Olivieri, A.; Benevolo, G.; Capra, A.; et al. Carfilzomib, cyclophosphamide and dexamethasone for newly diagnosed, high-risk myeloma patients not eligible for transplant: A pooled analysis of two studies. Haematologica 2020. [CrossRef]

61. Mateos, M.-V.; Ocio, E.M.; Sureda Balari, A.; Oriol, A.; Garcia, E.G.; Moreno, M.J.; Granell, M.; Escalante, F.; Gonzalez De La Calle, V.; Rosinol Dachs, L.; et al. Randomized Phase 2 Study of Weekly Carfilzomib $70 \mathrm{Mg} / \mathrm{m} 2$ and Dexamethasone Plus/Minus Cyclophosphamide in Relapsed and/or Refractory Multiple Myeloma (RRMM) Patients (GEM-KyCyDex). Blood 2020, 136, 8-9. [CrossRef]

62. Ghiringhelli, F.; Menard, C.; Puig, P.E.; Ladoire, S.; Roux, S.; Martin, F.; Solary, E.; Le Cesne, A.; Zitvogel, L.; Chauffert, B. Metronomic cyclophosphamide regimen selectively depletes CD4+CD25+ regulatory $\mathrm{T}$ cells and restores T and NK effector functions in end stage cancer patients. Cancer Immunol. Immunother. 2007, 56, 641-648. [CrossRef] [PubMed]

63. Swan, D.; Gurney, M.; Krawczyk, J.; Ryan, A.E.; O’Dwyer, M. Beyond DNA Damage: Exploring the Immunomodulatory Effects of Cyclophosphamide in Multiple Myeloma. Hemasphere 2020, 4, e350. [CrossRef] [PubMed]

64. Schey, S.A.; Morgan, G.J.; Ramasamy, K.; Hazel, B.; Ladon, D.; Corderoy, S.; Jenner, M.; Phekoo, K.; Boyd, K.; Davies, F.E. The addition of cyclophosphamide to lenalidomide and dexamethasone in multiply relapsed/refractory myeloma patients; a phase I/II study. Br. J. Haematol. 2010, 150, 326-333. [CrossRef] [PubMed]

65. Reece, D.E.; Masih-Khan, E.; Atenafu, E.G.; Jimenez-Zepeda, V.H.; Anglin, P.; Chen, C.; Kukreti, V.; Mikhael, J.R.; Trudel, S. Phase I-II trial of oral cyclophosphamide, prednisone and lenalidomide for the treatment of patients with relapsed and refractory multiple myeloma. Br. J. Haematol. 2015, 168, 46-54. [CrossRef] [PubMed]

66. Nijhof, I.S.; Franssen, L.E.; Levin, M.D.; Bos, G.M.J; Broijl, A.; Klein, S.K.; Koene, H.R.; Bloem, A.C.; Beeker, A.; Faber, L.M.; et al. Phase $1 / 2$ study of lenalidomide combined with low-dose cyclophosphamide and prednisone in lenalidomide-refractory multiple myeloma. Blood 2016, 128, 2297-2306. [CrossRef] [PubMed]

67. Franssen, L.E.; Nijhof, I.S.; Bjorklund, C.C.; Chiu, H.; Doorn, R.; van Velzen, J.; Emmelot, M.; van Kessel, B.; Levin, M.D.; Bos, G.M.J.; et al. Lenalidomide combined with low-dose cyclophosphamide and prednisone modulates Ikaros and Aiolos in lymphocytes, resulting in immunostimulatory effects in lenalidomide-refractory multiple myeloma patients. Oncotarget 2018, 9 , 34009-34021. [CrossRef] [PubMed]

68. Le, D.T.; Jaffee, E.M. Regulatory T-cell Modulation Using Cyclophosphamide in Vaccine Approaches: A Current Perspective. Cancer Res. 2012, 72, 3439-3444. [CrossRef] [PubMed]

69. Larocca, A.; Montefusco, V.; Bringhen, S.; Rossi, D.; Crippa, C.; Mina, R.; Galli, M.; Marcatti, M.; La Verde, G.; Giuliani, N.; et al. Pomalidomide, cyclophosphamide, and prednisone for relapsed/refractory multiple myeloma: A multicenter phase $1 / 2$ openlabel study. Blood 2013, 122, 2799-2806. [CrossRef]

70. Lee, H.S.; Kim, K.; Kim, S.J.; Lee, J.J.; Kim, I.; Kim, J.S.; Eom, H.S.; Yoon, D.H.; Suh, C.; Shin, H.J.; et al. Pomalidomide, cyclophosphamide, and dexamethasone for elderly patients with relapsed and refractory multiple myeloma: A study of the Korean Multiple Myeloma Working Party (KMMWP-164 study). Am. J. Hematol. 2020. [CrossRef]

71. Trudel, S.; Tessoulin, B.; Jullien, M.; Blin, N.; Gastinne, T.; Mahe, B.; Dubruille, V.; Bonnet, A.; Lok, A.; Chevallier, P.; et al. Pomalidomide, cyclophosphamide, and dexamethasone for relapsed/refractory multiple myeloma patients in a real-life setting: A single-center retrospective study. Ann. Hematol. 2019, 98, 1441-1447. [CrossRef] [PubMed]

72. Baz, R.C.; Martin, T.G., 3rd; Lin, H.Y.; Zhao, X.; Shain, K.H.; Cho, H.J.; Wolf, J.L.; Mahindra, A.; Chari, A.; Sullivan, D.M.; et al. Randomized multicenter phase 2 study of pomalidomide, cyclophosphamide, and dexamethasone in relapsed refractory myeloma. Blood 2016, 127, 2561-2568. [CrossRef] [PubMed]

73. Richardson, P.G.; Oriol, A.; Beksac, M.; Liberati, A.M.; Galli, M.; Schjesvold, F.; Lindsay, J.; Weisel, K.; White, D.; Facon, T.; et al. Pomalidomide, bortezomib, and dexamethasone for patients with relapsed or refractory multiple myeloma previously treated with lenalidomide (OPTIMISMM): A randomised, open-label, phase 3 trial. Lancet Oncol. 2019, 20, 781-794. [CrossRef]

74. Garderet, L.; Kuhnowski, F.; Berge, B.; Roussel, M.; Escoffre-Barbe, M.; Lafon, I.; Facon, T.; Leleu, X.; Karlin, L.; Perrot, A.; et al. Pomalidomide, cyclophosphamide, and dexamethasone for relapsed multiple myeloma. Blood 2018, 132, 2555-2563. [CrossRef] [PubMed] 
75. Weisel, K.C.; Scheid, C.; Zago, M.; Besemer, B.; Mai, E.K.; Haenel, M.; Duerig, J.; Munder, M.; Lindemann, H.W.; Seckinger, A.; et al. Addition of cyclophosphamide on insufficient response to pomalidomide and dexamethasone: Results of the phase II PERSPECTIVE Multiple Myeloma trial. Blood Cancer J. 2019, 9, 45. [CrossRef]

76. Van Oekelen, O.; Parekh, S.; Cho, H.J.; Vishnuvardhan, N.; Madduri, D.; Richter, J.; Ip, C.; Lau, K.; Florendo, E.; Mancia, I.S.; et al. A phase II study of pomalidomide, daily oral cyclophosphamide, and dexamethasone in relapsed/refractory multiple myeloma. Leuk. Lymphoma 2020, 61, 2208-2215. [CrossRef]

77. Dimopoulos, M.A.; Terpos, E.; Boccadoro, M.; Delimpasi, S.; Beksac, M.; Katodritou, E.; Moreau, P.; Baldini, L.; Symeonidis, A.; Bila, J.; et al. Apollo: Phase 3 Randomized Study of Subcutaneous Daratumumab Plus Pomalidomide and Dexamethasone (D-Pd) Versus Pomalidomide and Dexamethasone (Pd) Alone in Patients (Pts) with Relapsed/Refractory Multiple Myeloma (RRMM). Blood 2020, 136, 5-6. [CrossRef]

78. Attal, M.; Richardson, P.G.; Rajkumar, S.V.; San-Miguel, J.; Beksac, M.; Spicka, I.; Leleu, X.; Schjesvold, F.; Moreau, P.; Dimopoulos, M.A.; et al. Isatuximab plus pomalidomide and low-dose dexamethasone versus pomalidomide and lowdose dexamethasone in patients with relapsed and refractory multiple myeloma (ICARIA-MM): A randomised, multicentre, open-label, phase 3 study. Lancet 2019, 394, 2096-2107. [CrossRef]

79. Dimopoulos, M.A.; Dytfeld, D.; Grosicki, S.; Moreau, P.; Takezako, N.; Hori, M.; Leleu, X.; LeBlanc, R.; Suzuki, K.; Raab, M.S.; et al. Elotuzumab plus Pomalidomide and Dexamethasone for Multiple Myeloma. N. Engl. J. Med. 2018, 379, 1811-1822. [CrossRef]

80. Sebag, M.; Bahlis, N.J.; Venner, C.P.; McCurdy, A.; Kouroukis, C.T.; Shustik, J.; Kotb, R.; White, D.J.; Stakiw, J.; Laferriere, N.B.; et al. A Randomized Phase II, Open Label, Study of Daratumumab, Weekly Low-Dose Oral Dexamethasone and Cyclophosphamide with or without Pomalidomide in Patients with Relapsed and Refractory Multiple Myeloma. Blood 2020, 136, 6. [CrossRef]

81. Hiraoka, N.; Kikuchi, J.; Yamauchi, T.; Koyama, D.; Wada, T.; Uesawa, M.; Akutsu, M.; Mori, S.; Nakamura, Y.; Ueda, T.; et al. Purine analog-like properties of bendamustine underlie rapid activation of DNA damage response and synergistic effects with pyrimidine analogues in lymphoid malignancies. PLoS ONE 2014, 9, e90675. [CrossRef] [PubMed]

82. Strumberg, D.; Harstrick, A.; Doll, K.; Hoffmann, B.; Seeber, S. Bendamustine hydrochloride activity against doxorubicin-resistant human breast carcinoma cell lines. Anticancer Drugs 1996, 7, 415-421. [CrossRef] [PubMed]

83. Leoni, L.M.; Bailey, B.; Reifert, J.; Bendall, H.H.; Zeller, R.W.; Corbeil, J.; Elliott, G.; Niemeyer, C.C. Bendamustine (Treanda) displays a distinct pattern of cytotoxicity and unique mechanistic features compared with other alkylating agents. Clin. Cancer Res. 2008, 14, 309-317. [CrossRef] [PubMed]

84. Barcellini, W.; Zaninoni, A.; Giannotta, J.A.; Fattizzo, B. New Insights in Autoimmune Hemolytic Anemia: From Pathogenesis to Therapy Stage 1. J. Clin. Med. 2020, 9, 3859. [CrossRef] [PubMed]

85. Castillo, J.J.; Advani, R.H.; Branagan, A.R.; Buske, C.; Dimopoulos, M.A.; D'Sa, S.; Kersten, M.J.; Leblond, V.; Minnema, M.C.; Owen, R.G.; et al. Consensus treatment recommendations from the tenth International Workshop for Waldenstrom Macroglobulinaemia. Lancet Haematol. 2020, 7, e827-e837. [CrossRef]

86. Sarvaria, A.; Saven, A. Novel therapeutics in hairy cell leukemia. Expert Rev. Hematol. 2019, 12, 983-987. [CrossRef]

87. Hallek, M. Chronic lymphocytic leukemia: 2017 update on diagnosis, risk stratification, and treatment. Am. J. Hematol. 2017, 92, 946-965. [CrossRef]

88. Cortelazzo, S.; Ponzoni, M.; Ferreri, A.J.M.; Dreyling, M. Mantle cell lymphoma. Crit. Rev. Oncol. Hematol. 2020, 153, 103038. [CrossRef]

89. Sorigue, M.; Canamero, E.; Sancho, J.M. Precision medicine in follicular lymphoma: Focus on predictive biomarkers. Hematol. Oncol. 2020, 38, 625-639. [CrossRef]

90. Sindel, A.; Al-Juhaishi, T.; Yazbeck, V. Marginal Zone Lymphoma: State-of-the-Art Treatment. Curr. Treat. Options Oncol. 2019, 20, 90. [CrossRef]

91. Ponisch, W.; Mitrou, P.S.; Merkle, K.; Herold, M.; Assmann, M.; Wilhelm, G.; Dachselt, K.; Richter, P.; Schirmer, V.; Schulze, A.; et al. Treatment of bendamustine and prednisone in patients with newly diagnosed multiple myeloma results in superior complete response rate, prolonged time to treatment failure and improved quality of life compared to treatment with melphalan and prednisone-A randomized phase III study of the East German Study Group of Hematology and Oncology (OSHO). J. Cancer Res. Clin. Oncol. 2006, 132, 205-212. [CrossRef] [PubMed]

92. Ponisch, W.; Rozanski, M.; Goldschmidt, H.; Hoffmann, F.A.; Boldt, T.; Schwarzer, A.; Ritter, U.; Rohrberg, R.; Schwalbe, E.; Uhlig, J.; et al. Combined bendamustine, prednisolone and thalidomide for refractory or relapsed multiple myeloma after autologous stem-cell transplantation or conventional chemotherapy: Results of a Phase I clinical trial. Br. J. Haematol. 2008, 143, 191-200. [CrossRef] [PubMed]

93. Ramasamy, K.; Hazel, B.; Mahmood, S.; Corderoy, S.; Schey, S. Bendamustine in combination with thalidomide and dexamethasone is an effective therapy for myeloma patients with end stage renal disease. Br. J. Haematol. 2011, 155, 632-634. [CrossRef]

94. Lentzsch, S.; O’Sullivan, A.; Kennedy, R.C.; Abbas, M.; Dai, L.; Pregja, S.L.; Burt, S.; Boyiadzis, M.; Roodman, G.D.; Mapara, M.Y.; et al. Combination of bendamustine, lenalidomide, and dexamethasone (BLD) in patients with relapsed or refractory multiple myeloma is feasible and highly effective: Results of phase 1/2 open-label, dose escalation study. Blood 2012, 119, 4608-4613. [CrossRef]

95. Berenson, J.R.; Yellin, O.; Bessudo, A.; Boccia, R.V.; Noga, S.J.; Gravenor, D.S.; Patel-Donnelly, D.; Siegel, R.S.; Kewalramani, T.; Gorak, E.J.; et al. Phase I/II trial assessing bendamustine plus bortezomib combination therapy for the treatment of patients with relapsed or refractory multiple myeloma. Br. J. Haematol. 2013, 160, 321-330. [CrossRef] [PubMed] 
96. Ponisch, W.; Heyn, S.; Beck, J.; Wagner, I.; Mohren, M.; Hoffmann, F.A.; Lange, T.; Schmalfeld, M.; Zehrfeld, T.; Schwarzer, A.; et al. Lenalidomide, bendamustine and prednisolone exhibits a favourable safety and efficacy profile in relapsed or refractory multiple myeloma: Final results of a phase 1 clinical trial OSHO-\#077. Br. J. Haematol. 2013, 162, 202-209. [CrossRef] [PubMed]

97. Ponisch, W.; Bourgeois, M.; Moll, B.; Heyn, S.; Jakel, N.; Wagner, I.; Rohrberg, R.; Hurtz, H.J.; Schmalfeld, M.; Assmann, M.; et al. Combined bendamustine, prednisone and bortezomib (BPV) in patients with relapsed or refractory multiple myeloma. J. Cancer Res. Clin. Oncol. 2013, 139, 499-508. [CrossRef] [PubMed]

98. Ludwig, H.; Kasparu, H.; Leitgeb, C.; Rauch, E.; Linkesch, W.; Zojer, N.; Greil, R.; Seebacher, A.; Pour, L.; Weissmann, A.; et al. Bendamustine-bortezomib-dexamethasone is an active and well-tolerated regimen in patients with relapsed or refractory multiple myeloma. Blood 2014, 123, 985-991. [CrossRef] [PubMed]

99. Rodon, P.; Hulin, C.; Pegourie, B.; Tiab, M.; Anglaret, B.; Benboubker, L.; Jardel, H.; Decaux, O.; Kolb, B.; Roussel, M.; et al. Phase II study of bendamustine, bortezomib and dexamethasone as second-line treatment for elderly patients with multiple myeloma: The Intergroupe Francophone du Myelome 2009-01 trial. Haematologica 2015, 100, e56-e59. [CrossRef]

100. Schey, S.; Brown, S.R.; Tillotson, A.L.; Yong, K.; Williams, C.; Davies, F.; Morgan, G.; Cavenagh, J.; Cook, G.; Cook, M.; et al. Bendamustine, thalidomide and dexamethasone combination therapy for relapsed/refractory myeloma patients: Results of the MUKone randomized dose selection trial. Br. J. Haematol. 2015, 170, 336-348. [CrossRef]

101. Kumar, S.K.; Krishnan, A.; LaPlant, B.; Laumann, K.; Roy, V.; Zimmerman, T.; Gertz, M.A.; Buadi, F.K.; Stockerl Goldstein, K.; Birgin, A.; et al. Bendamustine, lenalidomide, and dexamethasone (BRD) is highly effective with durable responses in relapsed multiple myeloma. Am. J. Hematol. 2015, 90, 1106-1110. [CrossRef]

102. Pozzi, S.; Gentile, M.; Sacchi, S.; Marcheselli, R.; Corso, A.; Cocito, F.; Musto, P.; Guarini, A.; Minoia, C.; Vincelli, I.; et al. Bendamustine, Low-dose dexamethasone, and lenalidomide (BdL) for the treatment of patients with relapsed/refractory multiple myeloma confirms very promising results in a phase I/II study. Leuk. Lymphoma 2017, 58, 552-559. [CrossRef] [PubMed]

103. Mey, U.J.; Brugger, W.; Schwarb, H.; Pederiva, S.; Schwarzer, A.; Dechow, T.; Jehner, P.; Rauh, J.; Taverna, C.J.; Schmid, M.; et al. Bendamustine, lenalidomide and dexamethasone (BRd) has high activity as 2(nd) -line therapy for relapsed and refractory multiple myeloma-a phase II trial. Br. J. Haematol. 2017, 176, 770-782. [CrossRef]

104. Beck, J.; Schwarzer, A.; Glaser, D.; Mugge, L.O.; Uhlig, J.; Heyn, S.; Kragl, B.; Mohren, M.; Hoffmann, F.A.; Lange, T.; et al. Lenalidomide in combination with bendamustine and prednisolone in relapsed/refractory multiple myeloma: Results of a phase 2 clinical trial (OSHO-\#077). J. Cancer Res. Clin. Oncol. 2017, 143, 2545-2553. [CrossRef]

105. Sivaraj, D.; Green, M.M.; Kang, Y.; Long, G.D.; Rizzieri, D.A.; Li, Z.; Garrett, A.H.; McIntyre, J.L.; Chao, N.J.; Gasparetto, C. Bendamustine, pomalidomide, and dexamethasone for relapsed and/or refractory multiple myeloma. Blood Cancer J. $2018,8,71$. [CrossRef] [PubMed]

106. Gramatzki, M.; Guenther, A.; Offidani, M.; Engelhardt, M.M.; Montefusco, V.; Patriarca, F.; Angelucci, E.; Salvini, M.; Pönisch, W.; Spada, S.; et al. Carfilzomib, bendamustine, and dexamethasone (KBd) in advanced multiple myeloma: The EMN09-trial. J. Clin. Oncol. 2018, 36, 8019. [CrossRef]

107. Mian, M.; Pescosta, N.; Badiali, S.; Cappelletto, P.C.; Marcheselli, L.; Luminari, S.; Patriarca, F.; Zambello, R.; Pascarella, A.; Tagariello, G.; et al. Phase II trial to investigate efficacy and safety of bendamustine, dexamethasone and thalidomide in relapsed or refractory multiple myeloma patients after treatment with lenalidomide and bortezomib. Br. J. Haematol. 2019, 185, 944-947. [CrossRef]

108. Dhakal, B.; D'Souza, A.; Hamadani, M.; Arce-Lara, C.; Schroeder, K.; Chhabra, S.; Shah, N.N.; Gauger, K.; Keaton, T.; Pasquini, M.; et al. Phase I/II trial of bendamustine, ixazomib, and dexamethasone in relapsed/refractory multiple myeloma. Blood Cancer J. 2019, 9, 56. [CrossRef] [PubMed]

109. Stewart, A.K.; Rajkumar, S.V.; Dimopoulos, M.A.; Masszi, T.; Spicka, I.; Oriol, A.; Hajek, R.; Rosinol, L.; Siegel, D.S.; Mihaylov, G.G.; et al. Carfilzomib, lenalidomide, and dexamethasone for relapsed multiple myeloma. N. Engl. J. Med. 2015, 372, 142-152. [CrossRef] [PubMed]

110. Dimopoulos, M.; Quach, H.; Mateos, M.V.; Landgren, O.; Leleu, X.; Siegel, D.; Weisel, K.; Yang, H.; Klippel, Z.; Zahlten-Kumeli, A.; et al. Carfilzomib, dexamethasone, and daratumumab versus carfilzomib and dexamethasone for patients with relapsed or refractory multiple myeloma (CANDOR): Results from a randomised, multicentre, open-label, phase 3 study. Lancet 2020, 396, 186-197. [CrossRef]

111. Miguel, J.S.; Weisel, K.; Moreau, P.; Lacy, M.; Song, K.; Delforge, M.; Karlin, L.; Goldschmidt, H.; Banos, A.; Oriol, A.; et al. Pomalidomide plus low-dose dexamethasone versus high-dose dexamethasone alone for patients with relapsed and refractory multiple myeloma (MM-003): A randomised, open-label, phase 3 trial. Lancet Oncol. 2013, 14, 1055-1066. [CrossRef]

112. Lendvai, N.; Hilden, P.; Devlin, S.; Landau, H.; Hassoun, H.; Lesokhin, A.M.; Tsakos, I.; Redling, K.; Koehne, G.; Chung, D.J.; et al. A phase 2 single-center study of carfilzomib $56 \mathrm{mg} / \mathrm{m} 2$ with or without low-dose dexamethasone in relapsed multiple myeloma. Blood 2014, 124, 899-906. [CrossRef]

113. Gentilini, F.; Brunetti, G.; Finsinger, P.; Chisini, M.; Cartoni, C.; Foa, R.; Petrucci, M.T. Bendamustine and dexamethasone are an effective salvage regimen for patients with advanced multiple myeloma in a Home Care Unit program. Leuk. Lymphoma 2016, 57, 1716-1718. [CrossRef] [PubMed]

114. Mark, T.M.; Reid, W.; Niesvizky, R.; Gergis, U.; Pearse, R.; Mayer, S.; Greenberg, J.; Coleman, M.; Van Besien, K.; Shore, T. A phase 1 study of bendamustine and melphalan conditioning for autologous stem cell transplantation in multiple myeloma. Biol. Blood Marrow Transpl. 2013, 19, 831-837. [CrossRef] [PubMed] 
115. Gomez-Arteaga, A.; Mark, T.M.; Guarneri, D.; Christos, P.J.; Gergis, U.; Greenberg, J.D.; Hsu, J.; Mayer, S.A.; Niesvizky, R.; Pearse, R.N.; et al. High-dose bendamustine and melphalan conditioning for autologous stem cell transplantation for patients with multiple myeloma. Bone Marrow Transpl. 2019, 54, 2027-2038. [CrossRef] [PubMed]

116. Martino, M.; Tripepi, G.; Messina, G.; Vincelli, I.D.; Console, G.; Recchia, A.G.; Gentile, M.; Molica, S.; Morabito, F. A phase II, single-arm, prospective study of bendamustine plus melphalan conditioning for second autologous stem cell transplantation in de novo multiple myeloma patients through a tandem transplant strategy. Bone Marrow Transpl. 2016, 51, 1197-1203. [CrossRef]

117. Mateos, M.V.; Oriol, A.; Rosinol, L.; de Arriba, F.; Puig, N.; Martin, J.; Martinez-Lopez, J.; Echeveste, M.A.; Sarra, J.; Ocio, E.; et al. Bendamustine, bortezomib and prednisone for the treatment of patients with newly diagnosed multiple myeloma: Results of a prospective phase 2 Spanish/PETHEMA trial. Haematologica 2015, 100, 1096-1102. [CrossRef]

118. Berdeja, J.G.; Bauer, T.; Arrowsmith, E.; Essell, J.; Murphy, P.; Reeves, J.A., Jr.; Boccia, R.V.; Donnellan, W.; Flinn, I. Phase II study of bendamustine, bortezomib and dexamethasone (BBD) in the first-line treatment of patients with multiple myeloma who are not candidates for high dose chemotherapy. Br. J. Haematol. 2017, 177, 254-262. [CrossRef] [PubMed]

119. Leng, S.; Bhutani, D.; Raza, S.; Assal, A.; Pan, S.; Hu, J.; Wei, A.; Mapara, M.; Lentzsch, S. Phase I/II study of carfilzomib, bendamustine, and dexamethasone (CBD) in patients with newly diagnosed multiple myeloma. Blood Cancer J. 2020, 10, 13. [CrossRef]

120. Wickstrom, M.; Nygren, P.; Larsson, R.; Harmenberg, J.; Lindberg, J.; Sjoberg, P.; Jerling, M.; Lehmann, F.; Richardson, P.; Anderson, K.; et al. Melflufen-a peptidase-potentiated alkylating agent in clinical trials. Oncotarget 2017, 8, 66641-66655. [CrossRef]

121. Richardson, P.; Bringhen, S.; Voorhees, P.; Plesner, T.; Mellqvist, U.; Reeves, B.; Paba-Prada, C.; Zubair, H.; Byrne, C.; Anderson, K.; et al. Melflufen plus dexamethasone in relapsed and refractory multiple myeloma (O-12-M1): A multicentre, international, open-label, phase 1-2 study. Lancet Haematol. 2020, 7, e395-e407. [CrossRef]

122. Mateos, M.V.; Oriol, A.; Larocca, A.; Otero, P.R.; Bladé, J.; Cavo, M.; Hassoun, H.; Leleu, X.; Alegre, A.; Maisel, C.; et al. Clinical activity of melflufen in patients with triple-class refractory multiple myeloma and poor-risk features in an updated analysis of HORIZON (OP-106), a phase 2 study in patients with relapsed/refractory multiple myeloma refractory to pomalidomide and/or daratumumab. ASH Annu. Meet. Abstr. 2019, 133, 1883.

123. Ocio, E.M.; Efebera, Y.A.; Granell, M.; Hajek, R.; Maisnar, V.; Karlin, L.; Mateos, M.V.; Richardson, P.G.; Oriol, A.; Norin, S.; et al. ANCHOR (OP-104): Updated efficacy and safety from a phase $1 / 2$ study of melflufen and dexamethasone plus bortezomib or daratumumab in patients with relapsed/refractory multiple myeloma (RRMM) refractory to an IMiD or a proteasome inhibitor (PI). In Proceedings of the 61st American Society of Hematology Annual Meeting, Orlando, FL, USA, 7-10 December $2019 ;$ p. 3124.

124. Chauhan, D.; Ray, A.; Viktorsson, K.; Spira, J.; Paba-Prada, C.; Munshi, N.; Richardson, P.; Lewensohn, R.; Anderson, K.C. In vitro and in vivo antitumor activity of a novel alkylating agent, melphalan-flufenamide, against multiple myeloma cells. Clin. Cancer Res. 2013, 19, 3019-3031. [CrossRef]

125. Hitzerd, S.M.; Verbrugge, S.E.; Ossenkoppele, G.; Jansen, G.; Peters, G.J. Positioning of aminopeptidase inhibitors in next generation cancer therapy. Amino Acids 2014, 46, 793-808. [CrossRef]

126. Moore, H.E.; Davenport, E.L.; Smith, E.M.; Muralikrishnan, S.; Dunlop, A.S.; Walker, B.A.; Krige, D.; Drummond, A.H.; Hooftman, L.; Morgan, G.J.; et al. Aminopeptidase inhibition as a targeted treatment strategy in myeloma. Mol. Cancer Ther. 2009, 8, 762-770. [CrossRef]

127. Wickstrom, M.; Larsson, R.; Nygren, P.; Gullbo, J. Aminopeptidase N (CD13) as a target for cancer chemotherapy. Cancer Sci. 2011, 102, 501-508. [CrossRef]

128. Ray, A.; Ravillah, D.; Das, D.S.; Song, Y.; Nordstrom, E.; Gullbo, J.; Richardson, P.G.; Chauhan, D.; Anderson, K.C. A novel alkylating agent Melflufen induces irreversible DNA damage and cytotoxicity in multiple myeloma cells. Br. J. Haematol. 2016, 174, 397-409. [CrossRef]

129. Slipicevic, A.; Munawar, U.; Aschan, J.; Lehmann, F.; Miettinen, J.; Huppunen, M.-E.; Bargou, R.C.; Nupponen, N.N.; Rodriguez, P.; Richardson, P.; et al. Melflufen efficacy in multiple myeloma with TP53 aberrations. In Proceedings of the American Association for Cancer Research (AACR) Annual Meeting, Virtual Annual Meeting II, Philadelphia, PA, USA, 22-24 June 2020 ; p. 1843.

130. Schjesvold, F.; Robak, P.; Pour, L.; Aschan, J.; Sonneveld, P. OCEAN: A randomized Phase III study of melflufen + dexamethasone to treat relapsed refractory multiple myeloma. Future Oncol. 2020, 16, 631-641. [CrossRef]

131. Ocio, E.M.; Efebera, Y.A.; Hájek, R.; Granell, M.; Maisnar, V.; Straub, J.; Eveillard, J.-R.; Karlin, L.; Ribrag, V.; Mateos, M.-V.; et al. ANCHOR (OP-104): Melflufen Plus Dexamethasone (dex) and Daratumumab (dara) or Bortezomib (BTZ) in Relapsed/Refractory Multiple Myeloma (RRMM) Refractory to an IMiD and/or a Proteasome Inhibitor (PI)-Updated Efficacy and Safety. Blood 2020, 136, 9-10. [CrossRef]

132. Durie, B.G.; Hoering, A.; Abidi, M.H.; Rajkumar, S.V.; Epstein, J.; Kahanic, S.P.; Thakuri, M.; Reu, F.; Reynolds, C.M.; Sexton, R.; et al. Bortezomib with lenalidomide and dexamethasone versus lenalidomide and dexamethasone alone in patients with newly diagnosed myeloma without intent for immediate autologous stem-cell transplant (SWOG S0777): A randomised, open-label, phase 3 trial. Lancet 2017, 389, 519-527. [CrossRef]

133. Facon, T.; Kumar, S.; Plesner, T.; Orlowski, R.Z.; Moreau, P.; Bahlis, N.; Basu, S.; Nahi, H.; Hulin, C.; Quach, H.; et al. Daratumumab plus Lenalidomide and Dexamethasone for Untreated Myeloma. N. Engl. J. Med. 2019, 380, 2104-2115. [CrossRef] [PubMed]

134. Richardson, P.G.; Oriol, A.; Larocca, A.; Blade, J.; Cavo, M.; Rodriguez-Otero, P.; Leleu, X.; Nadeem, O.; Hiemenz, J.W.; Hassoun, H.; et al. Melflufen and Dexamethasone in Heavily Pretreated Relapsed and Refractory Multiple Myeloma. J. Clin. Oncol. 2021, 39, 757-767. [CrossRef] [PubMed] 
135. Oliveira, V.; Mahajan, N.; Bates, M.L.; Tripathi, C.; Kim, K.Q.; Zaher, H.S.; Maggi, L.B., Jr.; Tomasson, M.H. The snoRNA target of $\mathrm{t}(4 ; 14)$ in multiple myeloma regulates ribosome biogenesis. FASEB BioAdv. 2019, 1, 404-414. [CrossRef]

136. Munshi, N.C.; Anderson, L.D., Jr.; Shah, N.; Madduri, D.; Berdeja, J.; Lonial, S.; Raje, N.; Lin, Y.; Siegel, D.; Oriol, A.; et al. Idecabtagene Vicleucel in Relapsed and Refractory Multiple Myeloma. N. Engl. J. Med. 2021, 384, 705-716. [CrossRef]

137. Topp, M.S.; Duell, J.; Zugmaier, G.; Attal, M.; Moreau, P.; Langer, C.; Kronke, J.; Facon, T.; Salnikov, A.V.; Lesley, R.; et al. Anti-B-Cell Maturation Antigen BiTE Molecule AMG 420 Induces Responses in Multiple Myeloma. J. Clin. Oncol. 2020, 38, 775-783. [CrossRef] 